\title{
Deregulations in the Cyclin-Dependent Kinase-9-Related Pathway in Cancer: Implications for Drug Discovery and Development
}

\author{
Gaetano Romano \\ College of Science and Technology, Department of Biology, Temple University, Bio Life Science Building, Suite 456, \\ 1900 North 12th Street, Philadelphia, PA 19122, USA
}

Correspondence should be addressed to Gaetano Romano; gromano@temple.edu

Received 23 April 2013; Accepted 19 May 2013

Academic Editors: L. Mutti and S. Patel

Copyright (C) 2013 Gaetano Romano. This is an open access article distributed under the Creative Commons Attribution License, which permits unrestricted use, distribution, and reproduction in any medium, provided the original work is properly cited.

The CDK9-related pathway is an important regulator of mammalian cell biology and is also involved in the replication cycle of several viruses, including the human immunodeficiency virus type 1. CDK9 is present in two isoforms termed CDK9-42 and CDK9-55 that bind noncovalently type T cyclins and cyclin $\mathrm{K}$. This association forms a heterodimer, where CDK9 carries the enzymatic site and the cyclin partner functions as a regulatory subunit. This heterodimer is the main component of the positive transcription elongation factor $b$, which stabilizes RNA elongation via phosphorylation of the RNA pol II carboxyl terminal domain. Abnormal activities in the CDK9-related pathway were observed in human malignancies and cardiac hypertrophies. Thus, the elucidation of the CDK9 pathway deregulations may provide useful insights into the pathogenesis and progression of human malignancies, cardiac hypertrophy, AIDS and other viral-related maladies. These studies may lead to the improvement of kinase inhibitors for the treatment of the previously mentioned pathological conditions. This review describes the CDK9-related pathway deregulations in malignancies and the development of kinase inhibitors in cancer therapy, which can be classified into three categories: antagonists that block the ATP binding site of the catalytic domain, allosteric inhibitors, and small molecules that disrupt protein-protein interactions.

\section{Introduction}

Cyclin-dependent kinase 9 (CDK9) is a member of the cdc2like serine/threonine kinase family and was identified in the early 1990s [1-3]. At that time, CDK9 was initially named PITALRE [1-3]. Overall, the Cdk9-related pathway comprises two isoforms termed CDK9-42 and CDK9-55 and four cyclin partners, such as cyclin T1, cyclin T2a, cyclin T2b, and cyclin K (Figure 1) (Table 1) [4-10]. The denominations 42 and 55 are related to the apparent molecular weight of the two CDK9 isoforms that were observed in Western blot analysis [410]. The noncovalent association between CDK9 and one of its cyclin partners gives rise to a heterodimer, in which CDK9 carries the enzymatic site and the cyclin functions as a regulatory subunit (Figure 2) [1-10]. The establishment of the heterodimer is essential to confer biological activity to the CDK9/cyclin partner complex [1-10]. The latter is quite stable [11]. This is in contrast to the monomeric CDK9, which is susceptible to a rather fast degradation [12]. For this reason, monomeric CDK9 molecules must form a transient complex with chaperone proteins HSP70, HSP90, and Cdc37, prior to the final association with the corresponding cyclin partners (Figure 3) [12].

CDKs are essential factors in mammalian cell biology (Table 2). Many CDKs are directly involved in the regulation of cell cycle, such as CDK1, CDK2, CDK3, CDK4, CDK6, and CDK11 [13, 14].

In contrast to all the other CDKs, CDK5 relies on the noncyclin partners p35 and p38 [15-17] and performs an important role in the orchestration of cellular senescence $[13,18-20]$, survival of neurons [15], neuronal death $[15,17$, $21,22]$, formation of dendrite synapses and extensions $[15,16]$, migration of neurons into the granule cell layer $[15,16]$, and inhibition of cell cycle reentry in postmitotic neurons [15]. 


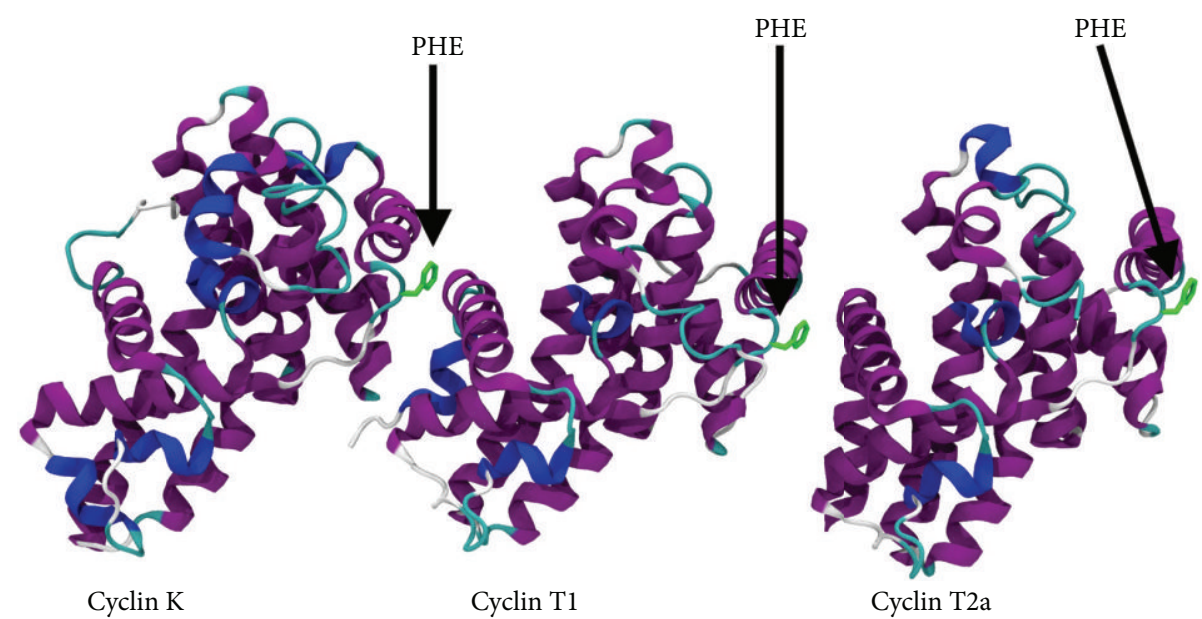

Figure 1: This figure displays the binding partners for Cdk9: cyclin K, cyclin T1, and cyclin T2a. Cyclin T2b is very similar to cyclin T2a and is not shown. Abbreviation: PHE: phenylalanine.

TABLE 1: Schematic representation of the Cdk9-related pathway.

\begin{tabular}{lc}
\hline Cdk9 isoforms & Cdk9-42; Cdk9-55 \\
Cyclin partners & Cyclin T1; cyclin T2a; cyclin T2b; cyclin K \\
Chaperone proteins & HSP70; HSP90; Cdc37 \\
\hline
\end{tabular}

CDK7, CDK8, and CDK9 are involved with the control of RNA-polymerase-II- (pol II-) mediated transcription [3, $10,13,23-28]$. In addition, CDK7 acts as a CDK-activating kinase (CAK) [13]. A recent study conducted on a human glioblastoma cell line showed that protein kinase C- (PKC-) $\iota$ phosphorylates CDK7 at Thr170 and CDK2 at Thr160 [14]. This finding indicates that human glioblastoma cells may proliferate via a novel PI (3)-kinase-/PKC-ı/Cdk7/cdk2mediated pathway [14]. Interestingly, CDK7 has the ability to phosphorylate the human estrogen receptor- $\alpha(\mathrm{ER} \alpha)$ at Ser294, which is one of the hallmarks of ER $\alpha$ activation in human breast cancer [29]. The aspects related to the CDK-mediated control of RNA pol II transcription will be discussed in greater detail in the following section, together with various factors that interact with the CDK9-related pathway.

CDK10 controls its own transcriptional activity through the association with the $\mathrm{C}$-ets- 2 transcription factor and takes part in the regulation of the $\mathrm{G}_{2}-\mathrm{M}$ cell cycle phase [30-33]. Recent findings seem to indicate that CDK10 might act as a putative tumor suppressor gene $[34,35]$ and that a reduced CDK10 expression is quite likely linked with the development and progression of hepatocellular carcinoma [35].

CDK11 regulates cell cycle progression, RNA-pol-IImediated transcription, splicing of premessenger RNA, and centriole duplication $[13,36-41]$.

In addition to CDK9, cyclin $\mathrm{K}$ associates with CDK12 and CDK13 [42-44]. These heterodimers are both implicated in the control of RNA-pol-II-mediated transcription [42-44]. CDK12 and CDK13 may also associate with L-type cyclins and take part in the regulation of alternative RNA splicing $[45,46]$.
CDK14 is also known either as PFTK1 or PFTAIRE1 and regulates cell cycle progression and cell proliferation [47-50]. CDK14 can associate with D-type cyclins [47-50] and cyclin Y $[51,52]$. Recent reports have demonstrated that CDK14 increases cell motility in human hepatocellular carcinoma cells $[53,54]$. Moreover, higher levels of CDK14 expression are correlated with enhanced chemoresistance in human primary oesophageal squamous cell carcinoma cells [55].

The CDK9-related pathway regulates a wide range of functions in mammalian cell biology $[1-12,24]$ and the replication program of numerous viral agents, such as the human immunodeficiency virus type 1 (HIV-1) and HIV-2 [25, 56], Epstein-Barr virus (EBV) [57], human T-lymphotropic virus type 1 (HTLV-1) [58, 59], human cytomegalovirus (hCMV) [60, 61], herpes simplex virus 1 (HSV-1) [62, 63], human adenovirus [64], and influenza A virus [65] (Table 2). Moreover, dysfunctions in the CDK9-related pathway are related with several forms of human tumors $[9,13,26-28,66-$ 68] and cardiac hypertrophy [69-75]. So far, many CDK inhibitors have been applied in clinical trials for the treatment of various malignancies (Table 3) [13, 26-28]. Studies are currently ongoing to evaluate the possibility of using CDK inhibitors in clinical trials for the treatment of AIDS, malaria, cardiac hypertrophy, type 2 diabetes, inflammatory kidney disease, and neurological disorders [13].

This paper focuses on the relevance of the deregulations in CDK9-related pathway in cancer and on the standpoint of the discovery and development of CDK inhibitors for cancer therapy.

\section{Biological Functions of the CDK9-Related Pathway}

The CDK9-related pathway is one of the primary factors in the regulation of mammalian cell biology [9, 13, 25, 27, 28]. Studies in the human and murine systems showed that CDK9 is present in all kinds of tissues and is highly expressed in terminally differentiated cells $[2,3,9]$. As anticipated, 


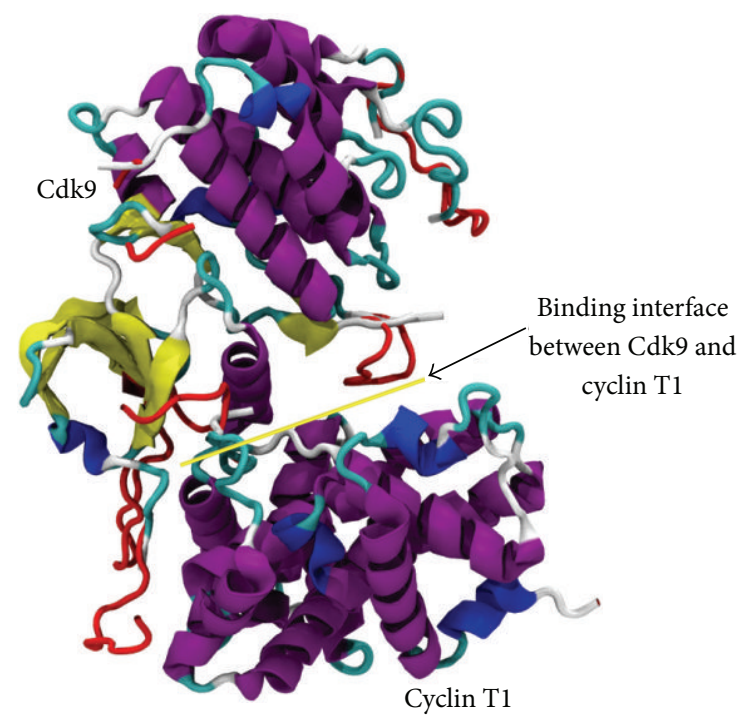

Figure 2: The Cdk9/cyclin T1 complex. The arrow depicts a yellow line, which shows the binding interface between Cdk9 and cyclin T1.

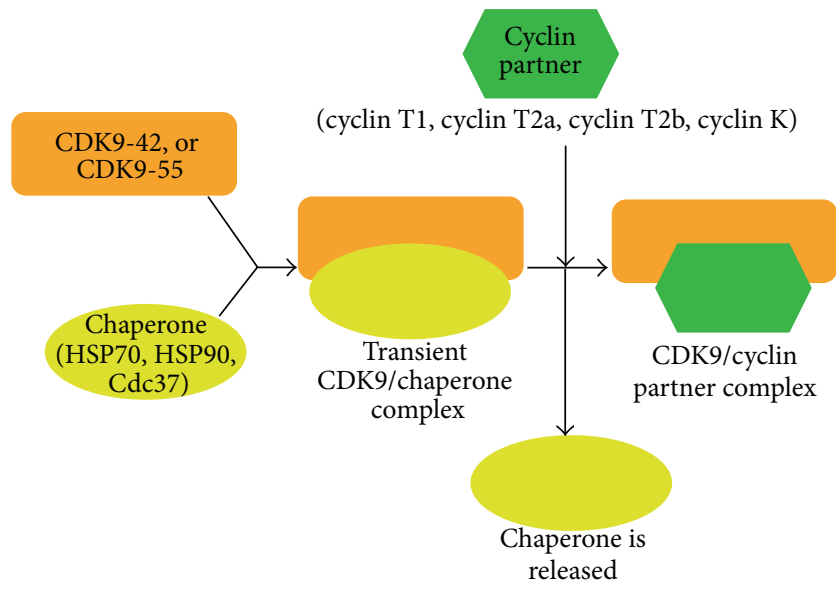

Figure 3: The components of the CDK9-related pathway.

there are two CDK9 isoforms in mammalian cells: CDK9-42 and CDK9-55 [4-6]. The CDK9-55 isoform has 117 additional amino acid residues in front of the amino terminus of CDK9-42 [4]. The genetic organization of the human CDK9 promoter comprises two transcription starts $[4,5]$. The human CDK9 promoter that encodes for CDK9-42 mRNA does not have a functional TATA box and contains a GC-rich sequence, and the region -352 to -1 includes the required transcriptional elements to sustain full promoter activity. These factors result in constitutive high levels of human CDK9-42 promoter activity, which is similar to a housekeeping gene promoter [7]. In contrast, the human CDK9-55 promoter contains a TATA box, which is situated approximately $500 \mathrm{bp}$ upstream of the human CDK9-42 transcription start $[4,7]$.

The CDK9-42 isoform is present both in the cell cytoplasm and nucleus [12], whereas CDK9-55 is predominantly localized in the cell nucleus [4]. Differential patterns of tissue distribution in the human and mouse model were observed between the two CDK9 isoforms [4, 5]. For instance, CDK9-42 expression has a bias for testis and spleen, whereas CDK9-55 is predominantly found in liver tissues, brain, and lung $[4,5]$. Similar findings in differential patterns of expression were observed in human and mouse cell culture systems. On one hand, CDK9-42 is primarily expressed in human cervical carcinoma HeLa cell line [76], human primary undifferentiated monocytes [8], and mouse NIH/3T3 fibroblasts [4]. On the other hand, CDK9-55 expression becomes predominant after induced differentiation of human primary monocytes along the macrophage lineage [8]. A considerable decline in CDK9-55 expression was reported following the activation of human lymphocytes, in which CDK9-42 becomes the predominant form [8]. Another study showed that CDK9-55 is primarily expressed in rat hepatocytes, when these cells are inside the liver, but CDK942 surmounts CDK9-55 expression once the rat hepatocytes are established in primary cell cultures [8]. Thus, the two CDK9 isoforms are differentially expressed depending on the cell signaling system and/or cell type. Lastly, several studies showed that CDK9-55 is associated with the regulation of the cell differentiation program of various tissues, such as the hematopoietic compartment $[4,5,8]$, the muscle $[68,77]$, and adipogenesis [78].

Both CDK9 isoforms can combine either with type $\mathrm{T}$ cyclins or cyclin $\mathrm{K}$ to generate a heterodimer (Tables 1 and 2), which is the principal constituent of the positive transcription elongation factor $\mathrm{b}$ (P-TEFb) (Figure 4) [5, 8, 25, 79-82]. The P-TEFb complex phosphorylates the carboxyl-terminus domain (CTD) of the RNA pol II, which, in turn, stabilizes the elongation of the RNA transcript [25, 80-82]. The kinase activity of P-TEFb is specifically inhibited by 5,6 -dichloro$1-\beta$-D-ribofuranosylbenzimidazole (DRB) $[5,8,25]$. The nonphosphorylated RNA pol II can start RNA transcription in the initial stages of the transcription complex assembly but is not able to support the full elongation of the nascent RNA transcript (Figure 4) $[25,80,83]$. This is due to the association between RNA pol II and the negative transcription elongation factor (N-TEF) (Figure 4) [80, 83]. The presence of the $\mathrm{P}-\mathrm{TEFb}$ accomplishes a dual function: the ejection of N-TEF from the transcription complex and the subsequent phosphorylation of the RNA pol II CTD, which becomes effective in maintaining the elongation of the nascent RNA transcript (Figure 4) $[25,80,83]$. The human RNA pol II CTD contains 52 repeats of the heptapeptide $\mathrm{Y}_{1} \mathrm{~S}_{2} \mathrm{P}_{3} \mathrm{~T}_{4} \mathrm{~S}_{5} \mathrm{P}_{6} \mathrm{~S}_{7}$ [84-86]. The nonphosphorylated RNA pol II is firmly linked with the various factors of the preinitiation complex, which include the TATA-binding protein (TBP) and the mediator complex [84-86]. A study conducted in the in vitro system showed that the CDK7-mediated phosphorylation of Ser5 of the heptapeptide reduces the binding affinity between the RNA pol II CTD and the other components of the preinitiation complex [84]. Then, the capping enzyme binds to the phosphorylated Ser5 CTD, and the RNA capping structure is associated with the nascent RNA transcript, which is approximately 25-30 nucleotides long [84]. However, Ser5 phosphorylation of RNA pol II CTD is not per se sufficient to stabilize the elongation of the RNA transcript, which also needs 


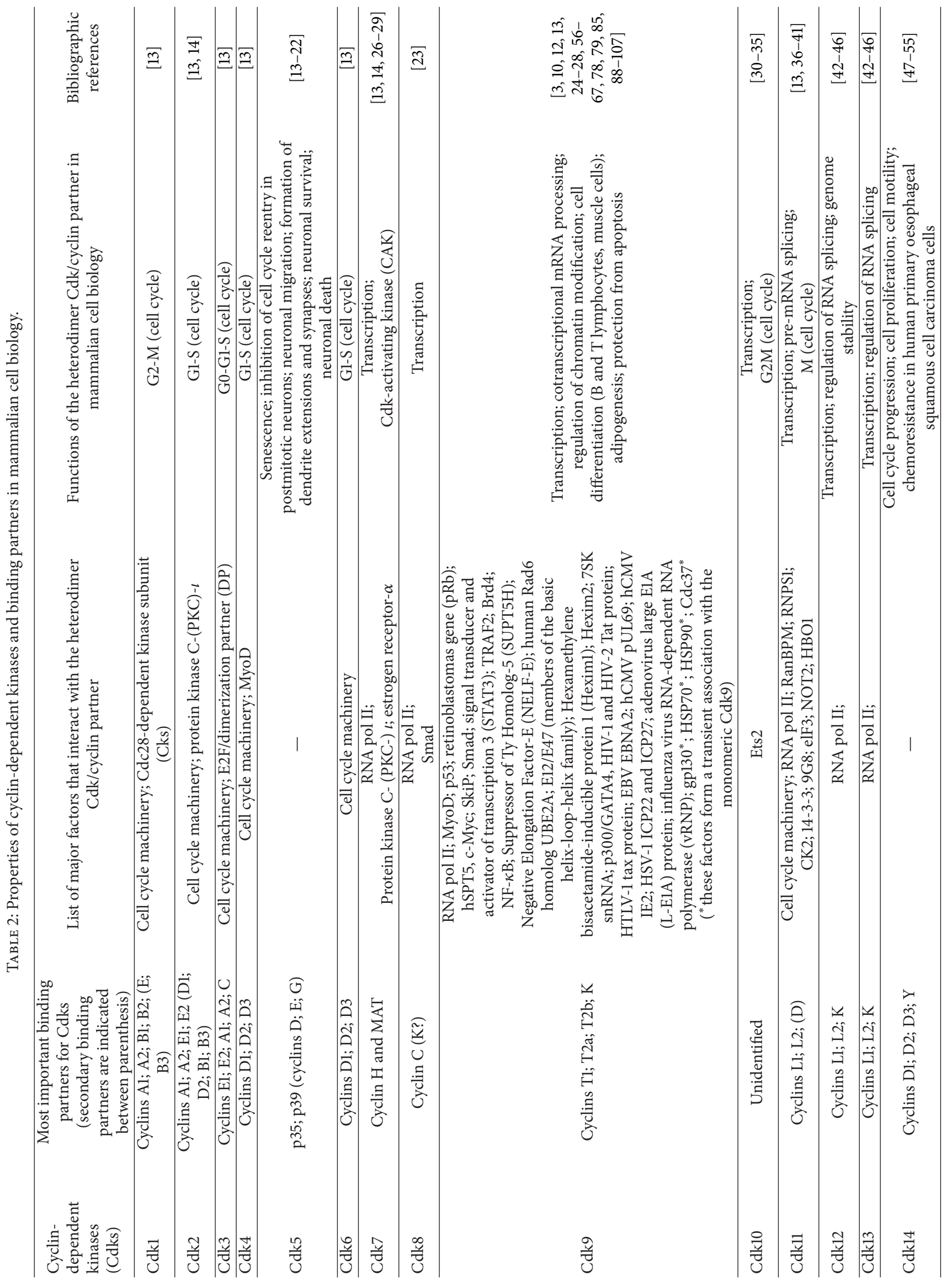


TABLE 3: CDK inhibitors utilized in clinical trials for the treatment of various types of malignancies (http://www.clinicaltrials.gov).

\begin{tabular}{|c|c|c|c|}
\hline Cdk inhibitors (Alias(es)) & Generation & Principal antikinase activity & Clinical trials for the treatment of tumors \\
\hline Seliciclib (CYC-202;R-roscovitine) & I & $\begin{array}{c}\text { Cdk1, 2, 5, 7, 9; CK1; GSK3A; DIRK1A; } \\
\text { ERK1 }\end{array}$ & $\begin{array}{c}\text { Phases I-II for nonsmall cell lung cancer (NSCLC) } \\
\text { and other solid tumors }\end{array}$ \\
\hline Alvocidib (flavopiridol) & $\mathrm{I}$ & Cdk1, 2, 4, 6, 7, 9; GSK3 $\beta$ & $\begin{array}{c}\text { Phases I-II for various types of cancers, such as } \\
\text { multiple myeloma, leukemia, lymphomas, } \\
\text { sarcoma, and solid tumors }\end{array}$ \\
\hline Dinaciclib (SCH727965) & I & $\mathrm{Cdk} 1,2,5,9$ & $\begin{array}{l}\text { Phases I-II for various solid tumors; phases I-II } \\
\text { for acute myelogenous leukemia, acute } \\
\text { lymphoblastic leukemia, mantle cell lymphoma, } \\
\text { and B cell chronic lymphocytic leukemia }\end{array}$ \\
\hline SNS-032 (BMS-387032) & I & Cdk1, 2, 4, 7, 9 & $\begin{array}{c}\text { Phases I-II for B-cell malignancies, nonsmall cell } \\
\text { lung cancer (NSCLC), advanced breast cancer, } \\
\text { and melanoma }\end{array}$ \\
\hline AG-024322 & I & Cdkl, 2, 4, 7 & $\begin{array}{l}\text { Phase I for non-Hodgkin's lymphoma and } \\
\text { advanced solid tumors }\end{array}$ \\
\hline $\mathrm{R} 547\left(\mathrm{R}_{0}-4584820\right)$ & I & $\mathrm{Cdk1}, 2,4,7$ & Phase I for advanced solid tumors \\
\hline P276-00 & II & Cdk1; Cdk4; Cdk9 & $\begin{array}{c}\text { Phases I-II for multiple myeloma and various } \\
\text { advanced refractory malignancies }\end{array}$ \\
\hline PD-0332991 & II & Cdk4, Cdk6 & $\begin{array}{c}\text { Phase I for non-Hodgkin's lymphoma, mantle cell } \\
\text { lymphoma, and other malignancies }\end{array}$ \\
\hline AT-7519 & II & Cdk2, Cdk4, Cdk5, Cdk9; GSK3 $\beta$ & $\begin{array}{l}\text { Phases I-IIa for advanced and/or metastatic solid } \\
\text { tumors and refractory non-Hodgkin's lymphoma }\end{array}$ \\
\hline RGB-286638 & II & Cdk1, Cdk2, Cdk4, Cdk5, Cdk7, Cdk9 & $\begin{array}{l}\text { Entering a phase I clinical trial for the treatment } \\
\text { of advanced solid tumors }\end{array}$ \\
\hline ZK 304709 & III & $\begin{array}{l}\text { Cdk1, 2, 4, 7, 9; VEGFR1, 2, 3; } \\
\text { PDGFR-b; Flt-3 }\end{array}$ & $\begin{array}{l}\text { Phase I trials for refractory and/or relapsed solid } \\
\text { tumors }\end{array}$ \\
\hline GPC-286199 (RGB-286199) & III & Cdk1, 2, 3, 5, 7, 9; CRKs & Preclinical stage \\
\hline JNJ-7706621 & III & Cdk1, 2, 3; Aurora A/B & Preclinical stage \\
\hline
\end{tabular}

the CDK9-mediated phosphorylation of Ser2 of the CTD heptapeptide [84]. Interestingly, an in vivo study showed that CDK7 and CDK9 were able to substitute each other in the phosphorylation of Ser5 and Ser 2 of the RNA pol II CTD [87], which is in contrast with the observation of the in vitro model $[84,87]$. This study was conducted on human glioblastoma and human prostate cancer cell lines and utilized siRNA molecules for the silencing of CDK9- and/or CDK7-related pathways [87]. The biological efficacy of the silencing of the two pathways was monitored by Western blot assay with antibodies that were specific either for phosphorylated Ser2 or phosphorylated Ser5 of the RNA pol II CTD [87]. The best inhibition of Ser2 and Ser5 phosphorylation required the simultaneous silencing of CDK9 and CDK7 [87]. Indeed, this finding may have significant implications both for the design of kinase inhibitors in cancer therapy and the development of a platform for microarray analysis of the two signaling systems in malignant cells [87].

The phosphorylation of the RNA pol II CTD is crucial for the CDK9-related pathway regulation of gene expression in mammalian cell biology $[13,25,27]$. Interestingly, the CDK9-related pathway also interacts with several other cellular and viral factors (Table 2) $[3,10,12,13,24-28,56-$ 67, 88-107]. These interactions may consist of phosphorylation and/or physical association between the CDK9related pathway and various cellular or viral components.
Some of these factors comprise MyoD, p53, pRb, cMyc, hSPT5, TRAF2, STAT3, SkiP, NK- $\kappa$ B, BRD4, SMAD, UBE2A, NELF-E, HEXIM1, HEXIM2, 7SK snRNA, gp130, HSP70, HSP90, Cdc37, E12/E47, hCMV UL69, EBV EBNA-2, HSV1 ICP22 and ICP27, HIV-1, and HIV-2 Tat protein (Table 2). As anticipated, the chaperone proteins HSP70, HSP90, and Cdc37 bind transiently and, therefore, stabilize the monomeric CDK9 preceding the association with one of its cyclin partners $[11,12]$. Interestingly, monomeric CDK9 has the ability to bind to the cytoplasmic region of the receptor for the interleukin-6 (IL-6) family of cytokines, which is termed gp130 [12, 98]. Such a phenomenon indicates a probable involvement of CDK9 as an intermediary in the regulation of the IL-6-related signal transduction pathway [12, 98].

The CDK9-mediated posttranslational modification of cellular factors constitutes an additional prospect for the genetic regulation of mammalian cell biology [13, 25, 27]. The same applies for the phosphorylation and/or association between the CDK9-related pathway and viral factors, which, once they are modified, take part in the gene regulation of the viral agent within the host cell $[13,25,27]$.

In addition, the CDK9-related pathway arbitrates the regulation of the cotranscriptional mRNA processing, chromatin modification, activation of quiescent $\mathrm{B}$ and/or $\mathrm{T}$ lymphocytes, cell differentiation, and cell survival (Table 2) $[24,66,67,78,79,85,99-106]$. The CDK9-related pathway is 


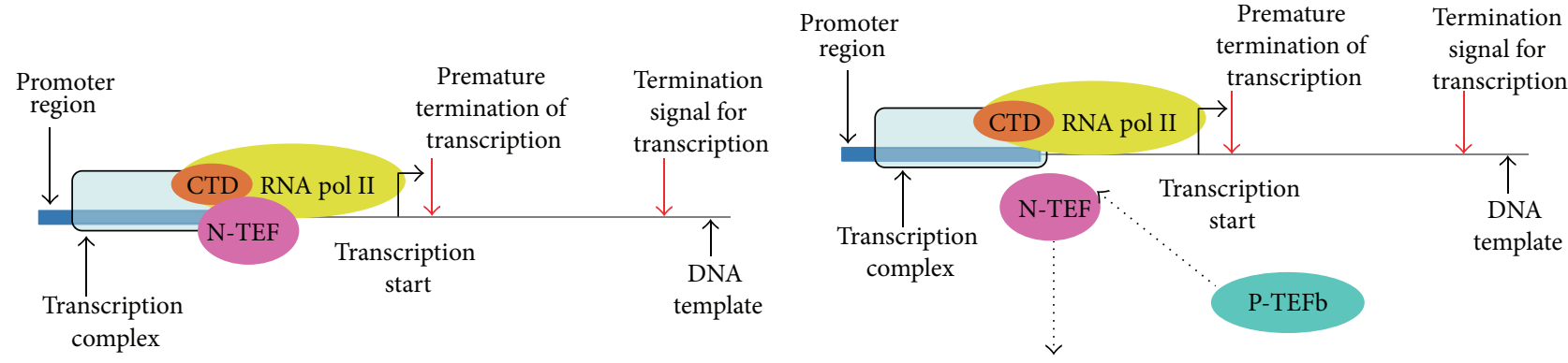

(a) Nonpermissive state for RNA elongation (b) State of transition

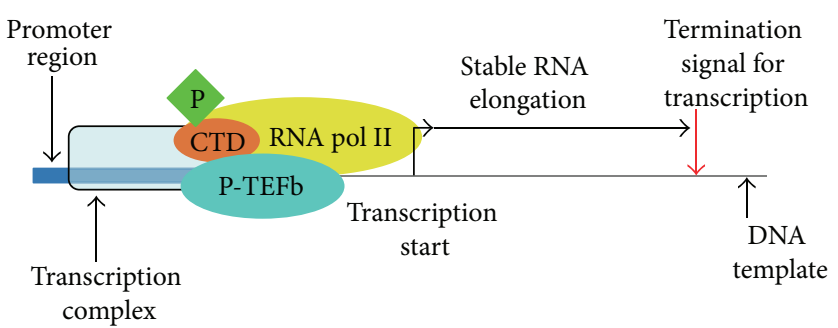

(c) Permissive state for RNA elongation

FIGURE 4: This figure describes the role of the P-TEFb complex in stabilizing RNA elongation. Panel (a) illustrates a nonpermissive state for RNA elongation. In this configuration, RNA pol II is associated with N-TEF, and the RNA pol II CTD is not phosphorylated. In this case, RNA transcription can start but stops prematurely. Panel (b) shows a state of transition, in which P-TEFb is about to substitute N-TEF in the transcription complex. P-TEFb contains the complex Cdk9/cyclin partner. Panel (c) exhibits a permissive state for RNA elongation. The presence of $\mathrm{P}-\mathrm{TEFb}$ in the transcription complex phosphorylates the RNA pol II CTD, which, in turn, allows for the stabilization of the RNA transcript elongation. Abbreviations: RNA pol II: RNA polymerase II; N-TEF: negative transcription factor; CTD: carboxyl terminal domain of RNA pol II; P-TEFb: positive transcription factor $b$.

a main player in the regulation of the differentiation program in the hematopoietic compartment $[4,5,8]$, muscle tissues [77, 107], central nervous system [67], and adipogenesis [78]. There is a great deal of interest in the involvement of the CDK9-related pathway and cell survival and/or protection from apoptosis. Previous studies demonstrated that the overexpression of a dominant negative CDK9 (CDK9-dn) increased susceptibility to apoptosis in human monocytes [12], human U-937 promonocytic cells, and human Jurkat T cell line [100].

Indeed, the CDK9-related signaling system is an important pathway in mammalian cell biology and covers a wide range of functions, which comprise cell survival and protection from apoptotic injuries. The latter might have important implication in the context of a deregulated CDK9 pathway in the establishment and maintenance of a transformed cell phenotype.

\section{The Deregulated CDK9 Pathway in Cancer}

Tumorigenesis is a multistep process, which requires a combination of genetic and epigenetic mutations, silencing of tumor suppressor genes, activation and/or overexpression of oncogenes, and environmental factors [108-113]. Several studies reported a connection between malignant cell transformation and abnormal antiapoptotic signaling systems, such as epidermal growth factor receptor (EGF-R), insulinlike growth factor-I receptor (IGF-1R), AKT-related pathway, autocrine/paracrine secreted Frizzled-related protein 2, and survivin [114-121]. In this respect, additional studies showed that a deregulated CDK9 signaling system might also have important implications in the development and/or maintenance of a malignant cell phenotype $[9,66,67,78,100,122]$. Aberrant patterns of cellular protein phosphorylation are indicative of hyperactive protein kinase pathways and are often observed both in tumors and many other maladies, such as neurological diseases, diabetes, inflammations, and infections [13, 26-28, 123, 124]. In particular, a deregulated CDK9 pathway increases the expression of myeloid leukemia cell differentiation protein (Mcl-1), as shown by studies on biopsies obtained from patients with either advanced chronic lymphocytic leukemia or multiple myeloma [122, 125-127]. Furthermore, deregulations in the CDK9-related pathway were reported in a number of human malignancies, such as lymphomas [66, 128], neuroblastoma [67], primary neuroectodermal tumor [67], rhabdomyosarcoma [68], and prostate cancer [129].

Increased expression levels of CDK9 and cyclin T1 were observed in $\mathrm{B}$ and $\mathrm{T}$ cell precursor-derived lymphomas, anaplastic large $\mathrm{T}$ cell lymphoma, and follicular lymphomas, while Hodgkin and Reed-Sternberg cells of classical Hodgkin's lymphoma were characterized by a strong nuclear staining for both proteins [66]. In addition, abnormal mRNA levels of CDK9 and cyclin T1 were found in Burkitt's lymphoma, diffuse large B cell lymphoma with germinal center phenotype, classical Hodgkin's lymphoma-derived cell lines, and follicular lymphoma [66]. 
These findings, taken together, indicate that $\mathrm{CDK} 9$, along with other CDKs, might be a suitable therapeutic target for cancer therapy.

\section{The Standpoint of Protein Kinase Development for Cancer Therapy}

The pharmacological inhibition of CDKs for the treatment of malignancies has indeed attracted a great deal of interest over the last years [13, 26-28]. The majority of protein kinase inhibitors are nucleoside analogs and aim at neutralizing the adenosine triphosphate (ATP) binding site situated in the CDK enzymatic moiety [130-133]. Many CDK inhibitors have been utilized in phase I and phase II clinical trials for the treatment of an ample variety of cancers (Table 3). In this respect, seliciclib and alvocidib belong to the first generation of CDK inhibitors and have been utilized in phase I and phase II clinical trials for the treatment of many types of tumors [13, 26-28]. However, these clinical trials reported a modest clinical efficacy in oncological patients treated either with seliciclib or alvocidib [13, 26-28].

The so-called first generation of CDK inhibitors is characterized by a wide-ranging anti-CDK activity and target at the same time CDK1, CDK2, CDK4, CDK6, CDK7, and CDK9 [13, 26-28]. In addition to seliciclib and alvocidib, the first generation of CDK inhibitors includes dinaciclib (or SCH727965), SNS-032 (or BMS-387032), AG-024322, and R-547 (or $\mathrm{R}_{0}$-4584820) (Table 3) [13, 26-28, 134].

The activity of the second generation of CDK inhibitors tends to aim at a more circumscribed group of CDKs, which usually comprises CDK4, CDK6, and/or CDK2 (Table 3) [13, 26-28]. The second generation of CDK inhibitors includes PD-0332991, P276-00, AT-7519, and RGB-286638 (Table 3) [13, 26-28, 135-144].

Lastly, the third generation of CDK inhibitors is directed against a number of CDKs, along with other types of protein kinases $[13,26-28,134]$. This strategy attempts to optimize the antitumor efficacy of the third generation of CDK inhibitors, which includes ZK 304709, GPC-286199 (or RGB-286199) and JNJ-7706621 (Table 3) [13, 26-28, 145-149]. For instance, the compound ZK 304709 was utilized in phase I clinical trials for the treatment of patients with refractory and/or relapsed solid tumors and inhibits CDK1, CDK2, CDK4, CDK7, CDK9, vascular endothelial growth factor receptors VEGFR-1, VEGFR-2, and VEGFR-3, platelet-derived growth factor receptor $\beta$ (PDGFR- $\beta$ ), and Flt3 (Table 3) $[145,146]$. GPC-286199 inhibits CDK1, CDK2, CDK3, CDK5, CDK7, CDK9, and CRK-related kinases [13, 26-28, 150, 151], whereas JNJ-7706621 targets CDK1, CDK2, CDK3, and Aurora-A/B kinases (Table 3) [13, 26-28, 147-149]. Both GPC-286199 and JNJ-7706621 are still at a preclinical stage testing.

\section{Future Directions for Drug Discovery and Development in Cancer Therapy}

As already mentioned, most of protein kinase inhibitors are nucleoside analogs and were designed to block the ATP binding site of the catalytic domain of various CDKs, such as alvocidib (or flavopiridol) and seliciclib [13, 26-28]. However, this therapeutic approach is associated with toxicity [13]. In addition, alvocidib and seliciclib exhibited a modest pharmacological activity in clinical trials for the treatment of patients with different kinds of tumors [13]. Several reasons may account for the toxicity of the two compounds [13]. One of these reasons might be related to the targeting of the ATP binding site of the CDK enzymatic domain, which has a conserved structure among protein kinases [152]. Thus, nucleoside analog CDK inhibitors become responsible for off-target effects, which may impair to some extent the normal functions of other types of protein kinases and, as a result, cause a considerable harm in normal cells and/or tissues [152]. In order to circumvent this issue, the field of drug design is developing the so-called allosteric inhibitors, which either modify the protein kinase conformation to inhibit the function of the CDK ATP binding site [153] or compete directly with the binding of the regulatory subunit of the kinase to the protein substrate [153-157]. Some examples of allosteric kinase inhibitors that impair ATP binding to the catalytic site comprise Gleevec (imatinib mesylate), BIRB796 (Doramapimod), BAY43-9006 (Sorafenib or Nexavar), and AAL-993 [153]. Gleevec was designed to inhibit many types of tyrosine kinases, such as Bcr-Abl, stem cell factor receptor (cKit), and platelet-derived growth factor receptor (PDGF-R) [153]. BIRB796 targets serine/threonine kinase p38 MAPK [153]. BAY43-9006 is a Raf inhibitor, whereas AAL-993 is an antiangiogenic factor that suppresses the kinase activity of VEGF-1R, VEGF-R2, and VEGF-R3 [153]. Other socalled ATP noncompetitive allosteric inhibitors that interfere with the interaction between the regulatory subunit of the kinase and the protein substrate include PD09859, CMPD1, Coumarin derivatives G8935 and G0328, API-2, amino-functionalized quinoxaline 5, Pyrazinone derivative 14f, Akt-I-1, Thiadiazolines, Chloromethyl thienylketone 17, and BMS-345541 [153]. Specifically, PD09859 is an MEK inhibitor, whereas CMPD1 and Coumarin derivatives G8935 and G0328 target the extracellular signal regulated kinase (ERK) mitogen-activated protein kinases (MAPKs) [153]. The AKT pathway is inhibited by API-2, amino-functionalized quinoxaline 5, Pyrazinone derivative 14f, and Akt-I-1. Thiadiazolines and Chloromethyl thienylketone 17 impair the functions of Glycogen synthase kinase 3- $\beta$ [153]. Lastly, BMS-345541 competes with the binding between the protein substrate and threonine/serine I $\kappa$ B kinases [153].

Interestingly, other classes of protein kinase inhibitors are currently under development for the targeting of wide interfaces between two proteins [158-165]. On one hand, this approach holds great therapeutic potential, but, on the other hand, the formulation of molecules that have the ability to disrupt the interaction between two proteins poses a daunting challenge. In fact, the contact surfaces between two interacting proteins may be in the range of 1,500 to $3,000 \mathrm{~A}^{2}$ $[166,167]$, whereas the interactions between a protein and a small molecule typically involve contact surfaces that may vary from 300 to $1,000 \mathrm{~A}^{2}[168,169]$. Furthermore, contact interfaces between two interacting proteins are usually flat and do not have pockets and/or grooves, which may be quite 
normally found on surfaces of proteins that bind to small molecules [170]. However, several mutational studies showed that a small number of amino acid residues involved in holding together protein-protein interface account for most of the free energy for the binding [171-175]. These so-called hotspots are usually found at the center of the contact interface and take less than half of the total contact interface implicated in protein-protein interactions. For example, the binding interface between CDK9 and cyclin T1 is flat and hydrophobic (Figure 2) [176]. The hydrophobic residues that constitute the hydrophobic pocket in the binding region of CDK9 and cyclin T1 comprise Leucine 64 (CDK9), Phenylalanine 59 (CDK9), Isoleucine 67 (CDK9), Isoleucine 84 (CDK9), Isoleucine 99 (CDK9), and Phenylalanine 146 (cyclin T1). Phenylalanine 146 residue of cyclin $\mathrm{T} 1$ is also present among the other cyclin partners of CDK9, such as cyclin T2a, cyclin T2b, and cyclin K (Figure 1) [176]. Remarkably, studies conducted on Iron chelators ICL670 and ICL311 reported kinase activity inhibition following the separation of CDK9 from cyclin T1, which, in turn, resulted either in suppression of HIV-1 replication $[164,165]$ or repression of tumor growth in vitro and in animal models [177]. The exact mechanism of Iron chelator-mediated dissociation of the CDK9 and cyclin T1 complex is still under investigation.

As indicated by the studies on the binding interface between CDK9 and cyclin T1, almost identical hotspot regions might be in common among other protein-protein interacting surfaces, such as CDK7 and cyclin $\mathrm{H}$, for example, $[178,179]$. Other reports described the presence of promiscuous contact surfaces in a number of protein-protein interactions [180]. Therefore, the design of small molecules for the inhibition of protein-protein interactions is always susceptible to undesired off-target effects. Nevertheless, encouraging achievements were reported in designing small molecules that exhibited specific targeting for protein-protein interactions [181-184]. A number of inhibitors for protein-protein interfaces were developed for interleukin-2 (IL-2), Bcl-X $\mathrm{X}_{L}$, human protein double minute 2 (HDM2), human papilloma virus (HPV) transcription factor E2, membrane-anchored bacterial ZipA protein, and binding of tumor necrosis factor (TNF) to its receptors (TNFR1 and TNFR2) [158]. Other studies are aiming at producing new classes of macromolecules termed "bis-peptides", which have molecular weights ranging from 750 to $2000 \mathrm{Da}[185,186]$. Such bis-peptides have the ability to create large, extended preorganized surfaces, which may provide outstanding drug characteristics for the disruption of protein-protein interfaces $[185,186]$. This approach allowed for the synthesis of a functionalized bis-peptide that inhibited the ubiquitination of wild-type p53 in human liver cancer cell lines [187]. The bis-peptide reproduced the activation domain of the tumor suppressor gene p53 and was utilized to neutralize HDM2 in human liver cancer cell lines [187]. HDM2 is a human E3 ubiquitin ligase and a suppressor of p53 expression through ubiquitination. Therefore, the bispeptide-mediated disruption of HDM2/p53 binding caused the inhibition of wild-type p53 ubiquitination [187, 188]. The accumulation of wild-type p53 may subsequently trigger apoptosis in malignant cells $[187,188]$.

\section{Conclusion}

The CDK9-related pathway has emerged as a target of extreme for cancer therapy. Deregulations in this pathway were observed in a variety of human tumors, which may induce increased expression and/or hyperactivity of cellular oncogenic factors. In fact, the use of kinase inhibitor in clinical trials for the treatment of patients with chronic lymphocytic leukemia showed that the inhibition of CDK9and CDK7-related pathways was responsible for the decrease of the antiapoptotic factor Mcl-1 [125-127]. On these grounds, there is a keen interest in producing new compounds with enhanced specificity for CDK9- and/or CDK7-related pathways.

The field of drug design is currently striving to improve the therapeutic index of kinase inhibitors for cancer therapy, in order to minimize the toxicity associated with kinase inhibitors that block the ATP binding site of the catalytic domain of the enzyme. In this respect, drug designers are pursuing two main strategies: the engineering of allosteric kinase inhibitors and of inhibitors that disrupt proteinprotein interactions.

\section{Acknowledgments}

This paper is dedicated to the loving memory of Teresa Raucci Romano and Gaetano Romano. The author wishes to thank Dr. Nurit Pilpel for her helpful comments on the paper.

\section{References}

[1] X. Graña, A. de Luca, N. Sang et al., "PITALRE, a nuclear CDC2related protein kinase that phosphorylates the retinoblastoma protein in vitro," Proceedings of the National Academy of Sciences of the United States of America, vol. 91, no. 9, pp. 3834-3838, 1994.

[2] L. Bagella, T. K. MacLachlan, R. J. Buono et al., "Cloning of murine Cdk9/PITALRE and its tissue-specific expression in development," Journal of Cellular Physiology, vol. 177, no. 2, pp. 206-213, 1998.

[3] L. Bagella, P. Stiegler, A. de Luca et al., "Genomic organization, promoter analysis, and chromosomal mapping of the mouse gene encoding Cdk9," Journal of Cellular Biochemistry, vol. 78, no. 1, pp. 170-178, 2000.

[4] S. M. Shore, S. A. Byers, P. Dent, and D. H. Price, "Characterization of Cdk955 and differential regulation of two Cdk9 isoforms," Gene, vol. 350, no. 1, pp. 51-58, 2005.

[5] S. M. Shore, S. A. Byers, W. Maury, and D. H. Price, "Identification of a novel isoform of Cdk9," Gene, vol. 307, no. 1-2, pp. 175-182, 2003.

[6] C. Giacinti, A. Musarò, G. de Falco et al., "Cdk9-55: a new player in muscle regeneration," Journal of Cellular Physiology, vol. 216, no. 3, pp. 576-582, 2008.

[7] H. Liu and A. P. Rice, "Genomic organization and characterization of promoter function of the human CDK9 gene," Gene, vol. 252, no. 1-2, pp. 51-59, 2000.

[8] H. Liu and C. H. Herrmann, "Differential localization and expression of the Cdk9 42k and 55k isoforms," Journal of Cellular Physiology, vol. 203, no. 1, pp. 251-260, 2005. 
[9] A. De Luca, M. De Falco, A. Baldi, and M. G. Paggi, "Cyclin T: three forms for different roles in physiological and pathological functions," Journal of Cellular Physiology, vol. 194, no. 2, pp. 101107, 2003.

[10] T.-J. Fu, J. Peng, G. Lee, D. H. Price, and O. Flores, "Cyclin $\mathrm{K}$ functions as a CDK9 regulatory subunit and participates in RNA polymerase II transcription," Journal of Biological Chemistry, vol. 274, no. 49, pp. 34527-34530, 1999.

[11] B. O'Keeffe, Y. Fong, D. Chen, S. Zhou, and Q. Zhou, "Requirement for a kinase-specific chaperone pathway in the production of a Cdk9/cyclin $\mathrm{T} 1$ heterodimer responsible for $\mathrm{P}-\mathrm{TEFb}-$ mediated Tat stimulation of HIV-1 transcription," Journal of Biological Chemistry, vol. 275, no. 1, pp. 279-287, 2000.

[12] G. de Falco, L. M. Neri, M. de Falco et al., "Cdk9, a member of the cdc2-like family of kinases, binds to gp130, the receptor of the IL-6 family of cytokines," Oncogene, vol. 21, no. 49, pp. 7464-7470, 2002.

[13] M. Malumbres, P. Pevarello, M. Barbacid, and J. R. Bischoff, "CDK inhibitors in cancer therapy: what is next?" Trends in Pharmacological Sciences, vol. 29, no. 1, pp. 16-21, 2008.

[14] S. R. Desai, P. P. Pillai, R. S. Patel, A. N. McCray, H. Y. WinPiazza, and M. E. Acevedo-Duncan, "Regulation of Cdk7 activity through a phosphatidylinositol (3)-kinase/PKC-ı-mediated signaling cascade in glioblastoma," Carcinogenesis, vol. 33, no. 1, pp. 10-19, 2012.

[15] S. Jessberger, F. H. Gage, A. J. Eisch, and D. C. Lagace, "Making a neuron: Cdk5 in embryonic and adult neurogenesis," Trends in Neurosciences, vol. 32, no. 11, pp. 575-582, 2009.

[16] A. Tobias, S. Monika, and L. Vincent, "CDK5: the "pathfinder" for new born neurons in adult hippocampus?" Cell Adhesion and Migration, vol. 3, no. 4, pp. 319-321, 2009.

[17] J.-H. Lee, H.-S. Kim, S.-J. Lee, and K.-T. Kim, "Stabilization and activation of p53 induced by Cdk 5 contributes to neuronal cell death," Journal of Cell Science, vol. 120, no. 13, pp. 2259-2271, 2007.

[18] D. Mao and P. W. Hinds, "p35 is required for CDK5 activation in cellular senescence," Journal of Biological Chemistry, vol. 285, no. 19, pp. 14671-14680, 2010.

[19] B. Bai, Y. Liang, C. Xu et al., "Cyclin-dependent kinase 5mediated hyperphosphorylation of sirtuin-1 contributes to the development of endothelial senescence and atherosclerosis," Circulation, vol. 126, no. 6, pp. 729-740, 2012.

[20] A. Arif, "Extraneuronal activities and regulatory mechanisms of the atypical cyclin-dependent kinase Cdk5," Biochemical Pharmacology, vol. 84, no. 8, pp. 985-993, 2012.

[21] S. Hisanaga and A. Asada, "Cdk5-induced neuronal cell death: the activation of the conventional Rb-E2F G 1 pathway in postmitotic neurons," Cell Cycle, vol. 11, no. 11, article 2049, 2012.

[22] K. H. Chang, F. Vincent, and K. Shah, "Deregulated Cdk5 triggers aberrant activation of cell cycle kinases and phosphatases inducing neuronal death," Journal of Cell Science, vol. 125, no. 21, pp. 5124-5137, 2012.

[23] M. D. Galbraith, A. J. Donner, and J. M. Espinosa, "CDK8: a positive regulator of transcription," Transcription, vol. 1, no. 1, pp. 4-12, 2010.

[24] E. Leucci, G. de Falco, A. Onnis et al., "The role of the Cdk9/cyclin T1 complex in T cell differentiation," Journal of Cellular Physiology, vol. 212, no. 2, pp. 411-415, 2007.

[25] G. Romano, M. Kasten, G. de Falco et al., "Regulatory functions of Cdk9 and of cyclin T1 in HIV tat transactivation pathway gene expression," Journal of Cellular Biochemistry, vol. 75, no. 3, pp. 357-368, 1999.
[26] H. Weinmann and R. Metternich, "Drug discovery process for kinase inhibitors," ChemBioChem, vol. 6, no. 3, pp. 455-459, 2005.

[27] M. Malumbres and M. Barbacid, "Mammalian cyclin-dependent kinases," Trends in Biochemical Sciences, vol. 30, no. 11, pp. 630-641, 2005.

[28] M. Malumbres and M. Barbacid, "Cell cycle kinases in cancer," Current Opinion in Genetics and Development, vol. 17, no. 1, pp. 60-65, 2007.

[29] J. M. Held, D. J. Britton, G. K. Scott et al., "Ligand binding promotes CDK-dependent phosphorylation of ER-alpha on hinge serine 294 but inhibits ligand-independent phosphorylation of serine 305," Molecular Cancer Research, vol. 10, no. 8, pp. 1120 1132, 2012.

[30] M. Kasten and A. Giordano, "Cdk10, a Cdc2-related kinase, associates with the Ets2 transcription factor and modulates its transactivation activity," Oncogene, vol. 20, no. 15, pp. 1832-1838, 2001.

[31] J. C. Sergère, J. Y. Thuret, G. le Roux et al., "Human CDK10 gene isoforms," Biochemical and Biophysical Research Communications, vol. 276, no. 1, pp. 271-277, 2000.

[32] X.-Y. Zhong, X.-X. Xu, J. Yu et al., "Clinical and biological significance of Cdk10 in hepatocellular carcinoma," Gene, vol. 498, no. 1, pp. 68-74, 2012.

[33] L. Bagella, C. Giacinti, C. Simone, and A. Giordano, "Identification of murine cdk10: association with Ets2 transcription factor and effects on the cell cycle," Journal of Cellular Biochemistry, vol. 99, no. 3, pp. 978-985, 2006.

[34] J.-H. Yu, X. Y. Zhong, W.-G. Zhang et al., "CDK10 functions as a tumor suppressor gene and regulates survivability of biliary tract cancer cells," Oncology Reports, vol. 27, no. 4, pp. 12661276, 2012.

[35] S. Li, K. T. MacLachlan, A. De Luca et al., "The cdc-2-related kinase, PISSLRE, is essential for cell growth and acts in G2 phase of the cell cycle," Cancer Research, vol. 55, no. 18, pp. 3992-3995, 1995.

[36] J. H. Trembley, D. Hu, C. A. Slaughter, J. M. Lahti, and V. J. Kidd, "Casein kinase 2 interacts with cyclin-dependent kinase 11 (CDK11) in vivo and phosphorylates both the rna polymerase II carboxyl-terminal domain and CDk11 in vitro," Journal of Biological Chemistry, vol. 278, no. 4, pp. 2265-2270, 2003.

[37] D. Hu, A. Mayeda, J. H. Trembley, J. M. Lahti, and V. J. Kidd, "CDK11 complexes promote pre-mRNA splicing," Journal of Biological Chemistry, vol. 278, no. 10, pp. 8623-8629, 2003.

[38] J. Drogat, V. Migeot, E. Mommaerts et al., "Cdk11-cyclinL controls the assembly of the RNA polymerase II mediator complex," Cell Reports, vol. 2, no. 5, pp. 1068-1076, 2012.

[39] X. Kong, H. Gan, Y. Hao et al., "CDK11p58 phosphorylation of PAK1 Ser174 promotes DLC2 binding and roles on cell cycle progression," Journal of Biochemistry, vol. 146, no. 3, pp. 417$427,2009$.

[40] J. Drogat, V. Migeot, E. Mommaerts et al., "Cdk11-cyclinL controls the assembly of the RNA polymerase II mediator complex," Cell Reports, vol. 2, no. 5, pp. 1068-1076, 2012.

[41] N. Franck, E. Montembault, P. Romé, A. Pascal, J. Cremet, and R. Giet, "CDK11p58 is required for centriole duplication and Plk4 recruitment to mitotic centrosomes," PLos One, vol. 6, no. 1, Article ID e14600, 2011.

[42] J. Kohoutek and D. Blazek, "Cyclin K goes with Cdk12 and Cdk13," Cell Division, vol. 7, article 12, 2012. 
[43] J. Drogat and D. Hermand, "Gene-specific requirement of RNA polymerase II CTD phosphorylation," Molecular Microbiology, vol. 84, no. 6, pp. 995-1004, 2012.

[44] S. W. Cheng, M. A. Kuzyk, A. Moradian et al., "Interaction of cyclin-dependent kinase 12/CrkRS with cyclin $\mathrm{K} 1$ is required for the phosphorylation of the C-terminal domain of RNA polymerase II," Molecular Cell Biology, vol. 32, no. 22, pp. 46914704, 2012.

[45] H.-H. Chen, Y.-H. Wong, A.-M. Geneviere, and M.-J. Fann, "CDK13/CDC2L5 interacts with L-type cyclins and regulates alternative splicing," Biochemical and Biophysical Research Communications, vol. 354, no. 3, pp. 735-740, 2007.

[46] R. Berro, C. Pedati, K. Kehn-Hall et al., "CDK13, a new potential human immunodeficiency virus type 1 inhibitory factor regulating viral mRNA splicing," Journal of Virology, vol. 82, no. 14, pp. 7155-7166, 2008.

[47] F. Shu, S. Lv, Y. Qin et al., "Functional characterization of human PFTK1 as a cyclin-dependent kinase," Proceedings of the National Academy of Sciences of the United States of America, vol. 104, no. 22, pp. 9248-9253, 2007.

[48] E. Y.-T. Pang, A. H.-C. Bai, K. F. To et al., "Identification of PFTAIRE protein kinase 1 , a novel cell division cycle-2 related gene, in the motile phenotype of hepatocellular carcinoma cells," Hepatology, vol. 46, no. 2, pp. 436-445, 2007.

[49] P. Kaldis and M. Pagano, "Wnt signaling in mitosis," Developmental Cell, vol. 17, no. 6, pp. 749-750, 2009.

[50] G. Davidson and C. Niehrs, "Emerging links between CDK cell cycle regulators and Wnt signaling," Trends in Cell Biology, vol. 20, no. 8, pp. 453-460, 2010.

[51] M. Jiang, Y. Gao, T. Yang, X. Zhu, and J. Chen, "Cyclin Y, a novel membrane-associated cyclin, interacts with PFTK1," FEBS Letters, vol. 583, no. 13, pp. 2171-2178, 2009.

[52] D. Liu, S. Guest, and R. L. Finley Jr., "Why cyclin Y? A highly conserved cyclin with essential functions," Fly, vol. 4, no. 4, pp. 278-282, 2010.

[53] W. K. C. Leung, A. K. K. Ching, and N. Wong, "Phosphorylation of Caldesmon by PFTAIRE1 kinase promotes actin binding and formation of stress fibers," Molecular and Cellular Biochemistry, vol. 350, no. 1-2, pp. 201-206, 2011.

[54] W. K. C. Leung, A. K. K. Ching, A. W. H. Chan et al., "A novel interplay between oncogenic PFTK1 protein kinase and tumor suppressor TAGLN2 in the control of liver cancer cell motility," Oncogene, vol. 30, no. 44, pp. 4464-4475, 2011.

[55] H. Miyagaki, M. Yamasaki, H. Miyata et al., "Overexpression of PFTK1 predicts resistance to chemotherapy in patients with oesophageal squamous cell carcinoma," British Journal of Cancer, vol. 106, no. 5, pp. 947-954, 2012.

[56] C. H. Herrmann, R. G. Carroll, P. Wei, K. A. Jones, and A. P. Rice, "Tat-associated kinase, TAK, activity is regulated by distinct mechanisms in peripheral blood lymphocytes and promonocytic cell lines," Journal of Virology, vol. 72, no. 12, pp. 9881-9888, 1998.

[57] R. D. Palermo, H. M. Webb, A. Gunnell, and M. J. West, "Regulation of transcription by the Epstein-Barr virus nuclear antigen EBNA 2," Biochemical Society Transactions, vol. 36, no. 4, pp. 625-628, 2008.

[58] M. Zhou, H. Lu, H. Park, J. Wilson-Chiru, R. Linton, and J. N. Brady, "Tax interacts with P-TEFb in a novel manner to stimulate human T-lymphotropic virus type 1 transcription," Journal of Virology, vol. 80, no. 10, pp. 4781-4791, 2006.
[59] W. K. Cho, M. Zhou, K. J. Moon et al., "Modulation of the $\mathrm{Brd}$ /P-TEFb interaction by the human T-lymphotropic virus type 1 tax protein," Journal of Virology, vol. 81, no. 20, pp. 1117911186, 2007.

[60] S. Rechter, G. M. Scott, J. Eickhoff et al., "Cyclin-dependent kinases phosphorylate the cytomegalovirus RNA export protein pUL69 and modulate its nuclear localization and activity," Journal of Biological Chemistry, vol. 284, no. 13, pp. 8605-8613, 2009.

[61] A. J. Kapasi, C. L. Clark, K. Tran, and D. H. Spector, "Recruitment of cdk9 to the immediate-early viral transcriptosomes during human cytomegalovirus infection requires efficient binding to cyclin T1, a threshold level of IE2 86, and active transcription," Journal of Virology, vol. 83, no. 11, pp. 5904-5917, 2009.

[62] J. Q. Dai-Ju, L. Li, L. A. Johnson, and R. M. Sandri-Goldin, "ICP27 interacts with the C-terminal domain of RNA polymerase II and facilitates its recruitment to herpes simplex virus 1 transcription sites, where it undergoes proteasomal degradation during infection," Journal of Virology, vol. 80, no. 7, pp. 3567$3581,2006$.

[63] L. O. Durand and B. Roizman, "Role of cdk9 in the optimization of expression of the genes regulated by ICP22 of herpes simplex virus," Journal of Virology, vol. 82, no. 21, pp. 10591-10599, 2008.

[64] S. Vijayalingam and G. Chinnadurai, "Adenovirus L-E1A activates transcription through mediator complex-dependent recruitment of the super elongation complex," Journal of Virology, vol. 87, no. 6, pp. 3425-3434, 2013.

[65] J. Zhang, G. Li, and X. Ye, "Cyclin T1/CDK9 interacts with influenza a virus polymerase and facilitates its association with cellular RNA polymerase II," Journal of Virology, vol. 84, no. 24, pp. 12619-12627, 2010.

[66] C. Bellan, G. de Falco, S. Lazzi et al., "CDK9/CYCLIN T1 expression during normal lymphoid differentiation and malignant transformation," Journal of Pathology, vol. 203, no. 4, pp. 946952, 2004.

[67] G. de Falco, C. Bellan, A. D’Amuri et al., “Cdk9 regulates neural differentiation and its expression correlates with the differentiation grade of neuroblastoma and PNET tumors," Cancer Biology and Therapy, vol. 4, no. 3, pp. 277-281, 2005.

[68] C. Simone and A. Giordano, "Abrogation of signal-dependent activation of the cdk9/cyclin T2a complex in human RD rhabdomyosarcoma cells," Cell Death and Differentiation, vol. 14, no. 1, pp. 192-195, 2007.

[69] S. E. Johnatty, J. R. B. Dyck, L. H. Michael, E. N. Olson, and M. Abdellatif, "Identification of genes regulated during mechanical load-induced cardiac hypertrophy," Journal of Molecular and Cellular Cardiology, vol. 32, no. 5, pp. 805-815, 2000.

[70] A. Clerk, T. E. Cullingford, S. J. Fuller et al., "Signaling pathways mediating cardiac myocyte gene expression in physiological and stress responses," Journal of Cellular Physiology, vol. 212, no. 2, pp. 311-322, 2007.

[71] J. M. Gardin and M. S. Lauer, "Left ventricular hypertrophy: the next treatable, silent killer?" Journal of the American Medical Association, vol. 292, no. 19, pp. 2396-2398, 2004.

[72] D. Sayed, C. Hong, I. Y. Chen, J. Lypowy, and M. Abdellatif, "MicroRNAs play an essential role in the development of cardiac hypertrophy," Circulation Research, vol. 100, no. 3, pp. 416-424, 2007. 
[73] C. Dulac, A. A. Michels, A. Fraldi et al., "Transcriptiondependent association of multiple positive transcription elongation factor units to a HEXIM multimer," Journal of Biological Chemistry, vol. 280, no. 34, pp. 30619-30629, 2005.

[74] S. A. Byers, J. P. Price, J. J. Cooper, Q. Li, and D. H. Price, "HEXIM2, a HEXIM1-related protein, regulates positive transcription elongation factor b through association with 7SK," Journal of Biological Chemistry, vol. 280, no. 16, pp. 16360-16367, 2005.

[75] M. Sano, M. Abdellatif, H. Oh et al., "Activation and function of cyclin T-Cdk9 (positive transcription elongation factor-b) in cardiac muscle-cell hypertrophy," Nature Medicine, vol. 8, no. 11, pp. 1310-1317, 2002.

[76] S. P. Balk and K. E. Knudsen, "AR, the cell cycle, and prostate cancer," Nuclear Receptor Signaling, vol. 6, article e001, 2008.

[77] C. Giacinti, L. Bagella, P. L. Puri, A. Giordano, and C. Simone, "MyoD recruits the cdk9/cyclin T2 complex on myogenic-genes regulatory regions," Journal of Cellular Physiology, vol. 206, no. 3, pp. 807-813, 2006.

[78] I. Iankova, R. K. Petersen, J. Annicotte et al., "Peroxisome proliferator-activated receptor $\gamma$ recruits the positive transcription elongation factor $\mathrm{b}$ complex to activate transcription and promote adipogenesis," Molecular Endocrinology, vol. 20, no. 7, pp. 1494-1505, 2006.

[79] V. Brès, S. M. Yoh, and K. A. Jones, "The multi-tasking P-TEFb complex," Current Opinion in Cell Biology, vol. 20, no. 3, pp. 334340, 2008.

[80] X. Lin, R. Taube, K. Fujinaga, and B. M. Peterlin, "P-TEFb containing cyclin $\mathrm{K}$ and $\mathrm{Cdk} 9$ can activate transcription via RNA," Journal of Biological Chemistry, vol. 277, no. 19, pp. 1687316878, 2002.

[81] J. Garriga and X. Graña, "Cellular control of gene expression by T-type cyclin/CDK9 complexes," Gene, vol. 337, pp. 15-23, 2004.

[82] J. Kohoutek, "P-TEFb-the final frontier," Cell Division, vol. 4, article 19, 2009.

[83] D. H. Price, "P-TEFb, a cyclin-dependent kinase controlling elongation by RNA polymerase II," Molecular and Cellular Biology, vol. 20, no. 8, pp. 2629-2634, 2000.

[84] G. Lolli, "Binding to DNA of the RNA-polymerase II C-terminal domain allows discrimination between Cdk7 and Cdk9 phosphorylation," Nucleic Acids Research, vol. 37, no. 4, pp. 1260-1268, 2009.

[85] J. Pirngruber, A. Shchebet, L. Schreiber et al., "CDK9 directs $\mathrm{H} 2 \mathrm{~B}$ monoubiquitination and controls replication-dependent histone mRNA $3^{\prime}$-end processing," EMBO Reports, vol. 10, no. 8, pp. 894-900, 2009.

[86] K. Glover-Cutter, S. Larochelle, B. Erickson et al., "TFIIHassociated Cdk7 kinase functions in phosphorylation of C-terminal domain Ser7 residues, promoter-proximal pausing, and termination by RNA polymerase II," Molecular and Cellular Biology, vol. 29, no. 20, pp. 5455-5464, 2009.

[87] V. Caracciolo, G. Laurenti, G. Romano et al., "Flavopiridol induces phosphorylation of AKT in a human glioblastoma cell line, in contrast to siRNA-mediated silencing of Cdk9: implications for drug design and development," Cell Cycle, vol. 11, no. 6, pp. 1202-1216, 2012.

[88] C. Alarcón, A. Zaromytidou, Q. Xi et al., "Nuclear CDKs drive smad transcriptional activation and turnover in BMP and TGF$\beta$ pathways," Cell, vol. 139, no. 4, pp. 757-769, 2009.

[89] T. K. MacLachlan, N. Sang, A. de Luca et al., "Binding of CDK9 to TRAF2," Journal of Cellular Biochemistry, vol. 71, no. 4, pp. 467-478, 1998.
[90] B. Huang, X. D. Yang, M. M. Zhou, K. Ozato, and L. Chen, "Brd4 coactivates transcriptional activation of NF- $\kappa$ B via specific binding to acetylated RelA," Molecular and Cellular Biology, vol. 29, no. 5, pp. 1375-1387, 2009.

[91] Y. Sunagawa, T. Morimoto, T. Takaya et al., "Cyclin-dependent kinase- 9 is a component of the p300/GATA4 complex required for phenylephrine-induced hypertrophy in cardiomyocytes," Journal of Biological Chemistry, vol. 285, no. 13, pp. 9556-9568, 2010.

[92] S. Amini, A. Clavo, Y. Nadraga, A. Giordano, K. Khalili, and B. E. Sawaya, "Interplay between cdk9 and NF- $\kappa$ B factors determines the level of HIV-1 gene transcription in astrocytic cells," Oncogene, vol. 21, no. 37, pp. 5797-5803, 2002.

[93] H. F. Luecke and K. R. Yamamoto, “The glucocorticoid receptor blocks P-TEFb recruitment by NF $\kappa$ B to effect promoter-specific transcriptional repression," Genes and Development, vol. 19, no. 9, pp. 1116-1127, 2005.

[94] L. Amir-Zilberstein, E. Ainbinder, L. Toube, Y. Yamaguchi, H. Handa, and R. Dikstein, "Differential regulation of NF- $\kappa$ B by elongation factors is determined by core promoter type," Molecular and Cellular Biology, vol. 27, no. 14, pp. 5246-5259, 2007.

[95] C. Simone, L. Bagella, C. Bellan, and A. Giordano, "Physical interaction between $\mathrm{pRb}$ and cdk9/cyclinT2 complex," Oncogene, vol. 21, no. 26, pp. 4158-4165, 2002.

[96] J. B. Kim and P. A. Sharp, "Positive transcription elongation factor b phosphorylates hSPT5 and RNA polymerase II carboxylterminal domain independently of cyclin-dependent kinaseactivating kinase," Journal of Biological Chemistry, vol. 276, no. 15, pp. 12317-12323, 2001.

[97] S. K. Radhakrishnan and A. L. Gartel, "CDK9 phosphorylates p53 on serine residues 33, 315 and 392," Cell Cycle, vol. 5, no. 5, pp. 519-521, 2006.

[98] T. Hou, S. Ray, and A. R. Brasier, "The functional role of an interleukin 6-inducible CDK9.STAT3 complex in human $\gamma$-fibrinogen gene expression," Journal of Biological Chemistry, vol. 282, no. 51, pp. 37091-37102, 2007.

[99] J. Pirngruber, A. Shchebet, and S. A. Johnsen, "Insights into the function of the human P-TEFb component CDK9 in the regulation of chromatin modifications and co-transcriptional mRNA processing," Cell Cycle, vol. 8, no. 22, pp. 3636-3642, 2009.

[100] S. M. Foskett, R. Ghose, D. N. Tang, D. E. Lewis, and A. P. Rice, "Antiapoptotic function of Cdk9 (TAK/P-TEFb) in U937 promonocytic cells," Journal of Virology, vol. 75, no. 3, pp. 12201228, 2001.

[101] A. A. Michels and O. Bensaude, "RNA-driven cyclin-dependent kinase regulation: when CDK9/cyclin T subunits of $\mathrm{P}-\mathrm{TEFb}$ meet their ribonucleoprotein partners," Biotechnology Journal, vol. 3, no. 8, pp. 1022-1032, 2008.

[102] G. de Falco, E. Leucci, A. Onnis et al., "Cdk9/Cyclin T1 complex: a key player during the activation/differentiation process of normal lymphoid B cells," Journal of Cellular Physiology, vol. 215, no. 1, pp. 276-282, 2008.

[103] J. Garriga, J. Peng, M. Parreño, D. H. Price, E. E. Henderson, and X. Graña, "Upregulation of cyclin T1/CDK9 complexes during T cell activation," Oncogene, vol. 17, no. 24, pp. 3093-3102, 1998.

[104] Y. Xiao, J. Hendriks, P. Langerak, H. Jacobs, and J. Borst, “CD27 is acquired by primed B cells at the centroblast stage and promotes germinal center formation," Journal of Immunology, vol. 172, no. 12, pp. 7432-7441, 2004. 
[105] J. Jung, J. Choe, L. Li, and Y. S. Choi, "Regulation of CD27 expression in the course of germinal center B cell differentiation: the pivotal role of IL-10," European Journal of Immunology, vol. 30, no. 8, pp. 2437-2443, 2000.

[106] R. M. Marshall, D. Salerno, J. Garriga, and X. Graña, "Cyclin $\mathrm{T} 1$ expression is regulated by multiple signaling pathways and mechanisms during activation of human peripheral blood lymphocytes," Journal of Immunology, vol. 175, no. 10, pp. 64026411, 2005.

[107] C. Simone, P. Stiegler, L. Bagella et al., "Activation of MyoDdependent transcription by cdk9/cyclin T2," Oncogene, vol. 21, no. 26, pp. 4137-4148, 2002.

[108] D.-D. Gan, M. Macaluso, C. Cinti, K. Khalili, and A. Giordano, "How does a normal human cell become a cancer cell?" Journal of Experimental and Clinical Cancer Research, vol. 22, no. 4, pp. 509-516, 2003.

[109] G. Romano, "Development of safer gene delivery systems to minimize the risk of insertional mutagenesis-related malignancies: a critical issue for the field of gene therapy," ISRN Oncology, vol. 2012, Article ID 616310, 14 pages, 2012.

[110] A. Giordano, A. Rossi, G. Romano, and L. Bagella, "Tumor suppressor $\mathrm{pRb} 2 / \mathrm{p} 130$ gene and its derived product Spa310 spacer domain as perspective candidates for cancer therapy," Journal of Cellular Physiology, vol. 213, no. 2, pp. 403-406, 2007.

[111] A. Sun, L. Bagella, S. Tutton, G. Romano, and A. Giordano, "From G0 to $S$ phase: a view of the roles played by the retinoblastoma $(\mathrm{Rb})$ family members in the Rb-E2F pathway," Journal of Cellular Biochemistry, vol. 102, no. 6, pp. 1400-1404, 2007.

[112] A. Fucito, C. Lucchetti, A. Giordano, and G. Romano, "Genetic and epigenetic alterations in breast cancer: what are the perspectives for clinical practice?" International Journal of Biochemistry and Cell Biology, vol. 40, no. 4, pp. 565-575, 2008.

[113] A. Giordano, A. Fucito, G. Romano, and I. R. Marino, "Carcinogenesis and environment: the cancer stem cell hypothesis and implications for the development of novel therapeutics and diagnostics," Frontiers in Bioscience, vol. 12, no. 9, pp. 3475-3482, 2007.

[114] M. W. Pedersen, N. Pedersen, L. Damstrup et al., "Analysis of the epidermal growth factor receptor specific transcriptome: effect of receptor expression level and an activating mutation," Journal of Cellular Biochemistry, vol. 96, no. 2, pp. 412-427, 2005.

[115] G. Romano, "The complex biology of the receptor for the insulin-like growth factor-1," Drug News and Perspectives, vol. 16, no. 8, pp. 525-531, 2003.

[116] G. Romano, M. Prisco, T. Zanocco-Marani et al., "Dissociation between resistance to apoptosis and the transformed phenotype in IGF-I receptor signaling," Journal of Cellular Biochemistry, vol. 72, no. 2, pp. 294-310, 1999.

[117] M. Prisco, G. Romano, F. Peruzzi, B. Valentinis, and R. Baserga, "Insulin and IGF-I receptors signaling in protection from apoptosis," Hormone and Metabolic Research, vol. 31, no. 2-3, pp. 80-89, 1999.

[118] F. Peruzzi, M. Prisco, M. Dews et al., "Multiple signaling pathways of the insulin-like growth factor 1 receptor in protection from apoptosis," Molecular and Cellular Biology, vol. 19, no. 10, pp. 7203-7215, 1999.

[119] V. M. Gelfanov, G. S. Burgess, S. Litz-Jackson et al., “Transformation of interleukin-3-dependent cells without participation of Stat5/bcl-xL: cooperation of akt with raf/erk leads to p65 nuclear factor kB-mediated antiapoptosis involving c-IAP2," Blood, vol. 98, no. 8, pp. 2508-2517, 2001.
[120] J.-L. Lee, C.-T. Lin, L.-L. Chueh, and C.-J. Chang, "Autocrine/ paracrine secreted Frizzled-related protein 2 induces cellular resistance to apoptosis. A possible mechanism of mammary tumorigenesis," Journal of Biological Chemistry, vol. 279, no. 15, pp. 14602-14609, 2004.

[121] H.-N. Zhen, X. Zhang, P.-Z. Hu et al., "Survivin expression and its relation with proliferation, apoptosis, and angiogenesis in brain gliomas," Cancer, vol. 104, no. 12, pp. 2775-2783, 2005.

[122] R. Chen, M. J. Keating, V. Gandhi, and W. Plunkett, "Transcription inhibition by flavopiridol: mechanism of chronic lymphocytic leukemia cell death," Blood, vol. 106, no. 7, pp. 25132519, 2005.

[123] M. E. M. Noble, J. A. Endicott, and L. N. Johnson, "Protein kinase inhibitors: insights into drug design from structure," Science, vol. 303, no. 5665, pp. 1800-1805, 2004.

[124] D. J. Pratt, J. A. Endicott, and M. E. M. Noble, "The role of structure in kinase-targeted inhibitor design," Current Opinion in Drug Discovery and Development, vol. 7, no. 4, pp. 428-436, 2004.

[125] R. Chen, W. G. Wierda, S. Chubb et al., "Mechanism of action of SNS-032, a novel cyclin-dependent kinase inhibitor, in chronic lymphocytic leukemia," Blood, vol. 113, no. 19, pp. 4637-4645, 2009.

[126] W. G. Tong, R. Chen, W. Plunkett et al., "Phase I and pharmacologic study of SNS-032, a potent and selective Cdk2, 7, and 9 inhibitor, in patients with advanced chronic lymphocytic leukemia and multiple myeloma," Journal of Clinical Oncology, vol. 28, no. 18, pp. 3015-3022, 2010.

[127] R. Chen, L. Guo, Y. Chen, Y. Jiang, W. G. Wierda, and W. Plunkett, "Homoharringtonine reduced Mcl-1 expression and induced apoptosis in chronic lymphocytic leukemia," Blood, vol. 117, no. 1, pp. 156-164, 2011.

[128] K. Bettayeb, O. M. Tirado, S. Marionneau-Lambot et al., "Meriolins, a new class of cell death-inducing kinase inhibitors with enhanced selectivity for cyclin-dependent kinases," Cancer Research, vol. 67, no. 17, pp. 8325-8334, 2007.

[129] D. K. Lee, H. O. Duan, and C. Chang, "Androgen receptor interacts with the positive elongation factor P-TEFb and enhances the efficiency of transcriptional elongation," Journal of Biological Chemistry, vol. 276, no. 13, pp. 9978-9984, 2001.

[130] I. R. Hardcastle, B. T. Golding, and R. J. Griffin, "Designing inhibitors of cyclin-dependent kinases," Annual Review of Pharmacology and Toxicology, vol. 42, pp. 325-348, 2002.

[131] A. Huwe, R. Mazitschek, and A. Giannis, "Small molecules as inhibitors of cyclin-dependent kinases," Angewandte Chemie, vol. 42, no. 19, pp. 2122-2138, 2003.

[132] J. Wesierska-Gadek and V. Krystof, "Selective cyclin-dependent kinase inhibitors discriminating between cell cycle and transcriptional kinases: future reality or Utopia?" Annals of the New York Academy of Sciences, vol. 1171, pp. 228-241, 2009.

[133] A. M. Senderowicz, "Small-molecule cyclin-dependent kinase modulators," Oncogene, vol. 22, no. 43, pp. 6609-6620, 2003.

[134] S. Lapenna and A. Giordano, "Cell cycle kinases as therapeutic targets for cancer," Nature Reviews Drug Discovery, vol. 8, no. 7, pp. 547-566, 2009.

[135] J. P. Leonard, A. S. LaCasce, M. R. Smith et al., "Selective CDK4/6 inhibition with tumor responses by PD0332991 in patients with mantle cell lymphoma," Blood, vol. 119, no. 20, pp. 4597-6074, 2012.

[136] K. T. Flaherty, P. M. LoRusso, A. DeMichele et al., "Phase I, doseescalation trial of the oral cyclin-dependent kinase 4/6 inhibitor 
PD 0332991, administered using a 21-day schedule in patients with advanced cancer," Clinical Cancer Research, vol. 18, no. 2, pp. 568-576, 2012.

[137] G. K. Schwartz, P. M. Lorusso, M. A. Dickson et al., "Phase i study of PD 0332991, a cyclin-dependent kinase inhibitor, administered in 3-week cycles (Schedule 2/1)," British Journal of Cancer, vol. 104, no. 12, pp. 1862-1868, 2011.

[138] P. L. Toogood, P. J. Harvey, J. T. Repine et al., "Discovery of a potent and selective inhibitor of cyclin-dependent kinase 4/6," Journal of Medicinal Chemistry, vol. 48, no. 7, pp. 2388-2406, 2005.

[139] P. B. Mishra, A. S. Lobo, K. S. Joshi et al., "Molecular mechanisms of anti-tumor properties of P276-00 in head and neck squamous cell carcinoma," Journal of Translational Medicine, vol. 11, no. 1, article 42, 2013.

[140] K. S. Joshi, M. J. Rathos, P. Mahajan et al., "P276-00, a novel cyclin-dependent inhibitor induces G1-G2 arrest, shows antitumor activity on cisplatin-resistant cells and significant in vivo efficacy in tumor models," Molecular Cancer Therapeutics, vol. 6, no. 3, pp. 926-934, 2007.

[141] D. Mahadevan, R. Plummer, M. S. Squires et al., "A phase I pharmacokinetic and pharmacodynamic study of AT7519, a cyclin-dependent kinase inhibitor in patients with refractory solid tumors," Annals of Oncology, vol. 22, no. 9, pp. 2137-2143, 2011.

[142] M. S. Squires, L. Cooke, V. Lock et al., "AT7519, a cyclindependent kinase inhibitor, exerts its effects by transcriptional inhibition in leukemia cell lines and patient samples," Molecular Cancer Therapeutics, vol. 9, no. 4, pp. 920-928, 2010.

[143] M. S. Squires, R. E. Feltell, N. G. Wallis et al., "Biological characterization of AT7519, a small-molecule inhibitor of cyclin-dependent kinases, in human tumor cell lines," Molecular Cancer Therapeutics, vol. 8, no. 2, pp. 324-332, 2009.

[144] P. de Bruijn, I. M. G. Moghaddam-Helmantel, M. J. A. de Jonge et al., "Validated bioanalytical method for the quantification of RGB-286638, a novel multi-targeted protein kinase inhibitor, in human plasma and urine by liquid chromatography/tandem triple-quadrupole mass spectrometry," Journal of Pharmaceutical and Biomedical Analysis, vol. 50, no. 5, pp. 977-982, 2009.

[145] E. N. Scott, A. L. Thomas, L. R. Molife et al., "A phase i dose escalation study of the pharmacokinetics and tolerability of ZK 304709, an oral multi-targeted growth inhibitor (MTGIÜ), in patients with advanced solid tumours," Cancer Chemotherapy and Pharmacology, vol. 64, no. 2, pp. 425-429, 2009.

[146] J. S. Graham, R. Plummer, C. McCoy et al., "Open-label, nonrandomised, inter-individual dose escalation of ZK 304709 with the evaluation of safety, tolerability, pharmacokinetics, oral bioavailability and orientating efficacy after daily administration in patients with advanced cancer $(7 \mathrm{~d}$ treatment and $14 \mathrm{~d}$ recovery)," European Journal of Cancer, vol. 44, no. 15, pp. 21622168, 2008.

[147] A. Matsuhashi, T. Ohno, M. Kimura et al., "Growth suppression and mitotic defect induced by JNJ-7706621, an inhibitor of cyclin-dependent kinases and aurora kinases," Current Cancer Drug Targets, vol. 12, no. 6, pp. 625-639, 2012.

[148] S. Huang, P. J. Connolly, R. Lin, S. Emanuel, and S. A. Middleton, "Synthesis and evaluation of $\mathrm{N}$-acyl sulfonamides as potential prodrugs of cyclin-dependent kinase inhibitor JNJ7706621," Bioorganic and Medicinal Chemistry Letters, vol. 16, no. 14, pp. 3639-3641, 2006.
[149] S. Emanuel, C. A. Rugg, R. H. Gruninger et al., "The in vitro and in vivo effects of JNJ-7706621: a dual inhibitor of cyclindependent kinases and Aurora kinases," Cancer Research, vol. 65, no. 19, pp. 9038-9046, 2005.

[150] M. Tsuda and S. Tanaka, "Roles for crk in cancer metastasis and invasion," Genes Cancer, vol. 3, no. 5-6, pp. 334-340, 2012.

[151] N. Tikhmyanova, J. L. Little, and E. A. Golemis, "CAS proteins in normal and pathological cell growth control," Cellular and Molecular Life Sciences, vol. 67, no. 7, pp. 1025-1048, 2010.

[152] E. Missner, I. Bahr, V. Badock, U. Lücking, G. Siemeister, and P. Donner, "Off-target decoding of a multitarget kinase inhibitor by chemical proteomics," ChemBioChem, vol. 10, no. 7, pp. 11631174, 2009.

[153] M. A. Bogoyevitch and D. P. Fairlie, "A new paradigm for protein kinase inhibition: blocking phosphorylation without directly targeting ATP binding," Drug Discovery Today, vol. 12, no. 1516, pp. 622-633, 2007.

[154] J. Dietrich, C. Hulme, and L. H. Hurley, "The design, synthesis, and evaluation of 8 hybrid DFG-out allosteric kinase inhibitors: a structural analysis of the binding interactions of Gleevec $®$, Nexavar®, and BIRB-796," Bioorganic and Medicinal Chemistry, vol. 18, no. 15, pp. 5738-5748, 2010.

[155] M. A. Bogoyevitch, R. K. Barr, and A. J. Ketterman, "Peptide inhibitors of protein kinases-discovery, characterisation and use," Biochimica et Biophysica Acta, vol. 1754, no. 1-2, pp. 79-99, 2005.

[156] K. J. Cox, C. D. Shomin, and I. Ghosh, “Tinkering outside the kinase ATP box: allosteric (type IV) and bivalent (type V) inhibitors of protein kinases," Future Medicinal Chemistry, vol. 3, no. 1, pp. 29-43, 2011.

[157] R. Prudent and C. Cochet, "New protein kinase CK2 inhibitors: jumping out of the catalytic box," Chemistry and Biology, vol. 16, no. 2, pp. 112-120, 2009.

[158] J. A. Wells and C. L. McClendon, "Reaching for high-hanging fruit in drug discovery at protein-protein interfaces," Nature, vol. 450, no. 7172, pp. 1001-1009, 2007.

[159] A. L. Jochim and P. S. Arora, "Systematic analysis of helical protein interfaces reveals targets for synthetic inhibitors," ACS Chemical Biology, vol. 5, no. 10, pp. 919-923, 2010.

[160] P. Chène, "Drugs targeting protein-protein interactions," ChemMedChem, vol. 1, no. 4, pp. 400-411, 2006.

[161] L. Zhao and J. Chmielewski, "Inhibiting protein-protein interactions using designed molecules," Current Opinion in Structural Biology, vol. 15, no. 1, pp. 31-34, 2005.

[162] J. C. Fuller, N. J. Burgoyne, and R. M. Jackson, "Predicting druggable binding sites at the protein-protein interface," Drug Discovery Today, vol. 14, no. 3-4, pp. 155-161, 2009.

[163] S. R. Accordino, M. A. Morini, M. B. Sierra, J. A. R. Fris, G. A. Appignanesi, and A. Fernández, "Wrapping mimicking in druglike small molecules disruptive of protein-protein interfaces," Proteins, vol. 80, no. 7, pp. 1755-1765, 2012.

[164] Z. Debebe, T. Ammosova, M. Jerebtsova et al., "Iron chelators ICL670 and 311 inhibit HIV-1 transcription," Virology, vol. 367, no. 2, pp. 324-333, 2007.

[165] Z. Debebe, T. Ammosova, D. Breuer et al., "Iron chelators of the Di-2-pyridylketone thiosemicarbazone and 2-benzoylpyridine thiosemicarbazone series inhibit HIV-1 transcription: identification of novel cellular targets-iron, cyclin-dependent kinase (CDK) 2, and CDK9," Molecular Pharmacology, vol. 79, no. 1, pp. 185-196, 2011. 
[166] S. Jones and J. M. Thornton, "Principles of protein-protein interactions," Proceedings of the National Academy of Sciences of the United States of America, vol. 93, no. 1, pp. 13-20, 1996.

[167] L. L. Conte, C. Chothia, and J. Janin, "The atomic structure of protein-protein recognition sites," Journal of Molecular Biology, vol. 285, no. 5, pp. 2177-2198, 1999.

[168] A. C. Cheng, R. G. Coleman, K. T. Smyth et al., "Structure-based maximal affinity model predicts small-molecule druggability," Nature Biotechnology, vol. 25, no. 1, pp. 71-75, 2007.

[169] R. D. Smith, L. Hu, J. A. Falkner, M. L. Benson, J. P. Nerothin, and H. A. Carlson, "Exploring protein-ligand recognition with binding MOAD," Journal of Molecular Graphics and Modelling, vol. 24 , no. 6 , pp. $414-425,2006$.

[170] A. L. Hopkins and C. R. Groom, "The druggable genome," Nature Reviews Drug Discovery, vol. 1, no. 9, pp. 727-730, 2002.

[171] T. Clackson and J. A. Wells, "A hot spot of binding energy in a hormone-receptor interface," Science, vol. 267, no. 5196, pp. 383386, 1995.

[172] T. Clackson, M. H. Ultsch, J. A. Wells, and A. M. de Vos, "Structural and functional analysis of the 1:1 growth hormone:receptor complex reveals the molecular basis for receptor affinity," Journal of Molecular Biology, vol. 277, no. 5, pp. 11111128, 1998.

[173] Y. A. Muller, B. Li, H. W. Christinger, J. A. Wells, B. C. Cunningham, and A. M. De Vos, "Vascular endothelial growth factor: crystal structure and functional mapping of the kinase domain receptor binding site," Proceedings of the National Academy of Sciences of the United States of America, vol. 94, no. 14, pp. 7192-7197, 1997.

[174] C. D. Thanos, W. L. DeLano, and J. A. Wells, "Hot-spot mimicry of a cytokine receptor by a small molecule," Proceedings of the National Academy of Sciences of the United States of America, vol. 103, no. 42, pp. 15422-15427, 2006.

[175] I. S. Moreira, P. A. Fernandes, and M. J. Ramos, "Hot spots-a review of the protein-protein interface determinant amino-acid residues," Proteins, vol. 68, no. 4, pp. 803-812, 2007.

[176] S. Baumli, G. Lolli, E. D. Lowe et al., "The structure of P-TEFb (CDK9/cyclin T1), its complex with flavopiridol and regulation by phosphorylation," EMBO Journal, vol. 27, no. 13, pp. 19071918, 2008.

[177] M. Whitnall, J. Howard, P. Ponka, and D. R. Richardson, "A class of iron chelators with a wide spectrum of potent antitumor activity that overcomes resistance to chemotherapeutics," Proceedings of the National Academy of Sciences of the United States of America, vol. 103, no. 40, pp. 14901-14906, 2006.

[178] G. Lolli, E. D. Lowe, N. R. Brown, and L. N. Johnson, "The crystal structure of human CDK7 and its protein recognition properties," Structure, vol. 12, no. 11, pp. 2067-2079, 2004.

[179] G. Andersen, A. Poterszman, J. M. Egly, D. Moras, and J.-C. Thierry, "The crystal structure of human cyclin H," FEBS Letters, vol. 397, no. 1, pp. 65-69, 1996.

[180] W. L. DeLano, M. H. Ultsch, A. M. de Vos, and J. A. Wells, "Convergent solutions to binding at a protein-protein interface," Science, vol. 287, no. 5456, pp. 1279-1283, 2000.

[181] M. M. R. Arkin and J. A. Wells, "Small-molecule inhibitors of protein-protein interactions: progressing towards the dream," Nature Reviews Drug Discovery, vol. 3, no. 4, pp. 301-317, 2004.

[182] H. Yin and A. D. Hamilton, "Strategies for targeting proteinprotein interactions with synthetic agents," Angewandte Chemie, vol. 44, no. 27, pp. 4130-4163, 2005.
[183] D. C. Fry, "Protein-protein interactions as targets for small molecule drug discovery," Biopolymers, vol. 84, no. 6, pp. 535$552,2006$.

[184] M. Arkin, "Protein-protein interactions and cancer: small molecules going in for the kill," Current Opinion in Chemical Biology, vol. 9, no. 3, pp. 317-324, 2005.

[185] C. E. Schafmeister, Z. Z. Brown, and S. Gupta, "Shapeprogrammable macromolecules," Accounts of Chemical Research, vol. 41, no. 10, pp. 1387-1398, 2008.

[186] Z. Z. Brown, J. Alleva, and C. E. Schafmeister, "Solid-phase synthesis of functionalized bis-peptides," Biopolymers, vol. 96, no. 5, pp. 578-585, 2011.

[187] Z. Z. Brown, K. Akula, A. Arzumanyan et al., "A spiroligomer $\alpha$-helix mimic that binds HDM2, penetrates human cells and stabilizes HDM2 in cell culture," PLos One, vol. 7, no. 10, article e45948, 2012.

[188] J. C. Carry and C. Garcia-Echeverria, "Inhibitors of the p53/hdm2 protein-protein interaction-path to the clinic," Bioorganic \& Medicinal Chemistry Letters, vol. 23, no. 9, pp. 24802485, 2013. 


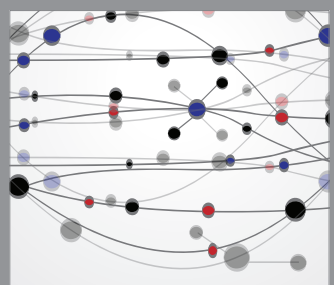

The Scientific World Journal
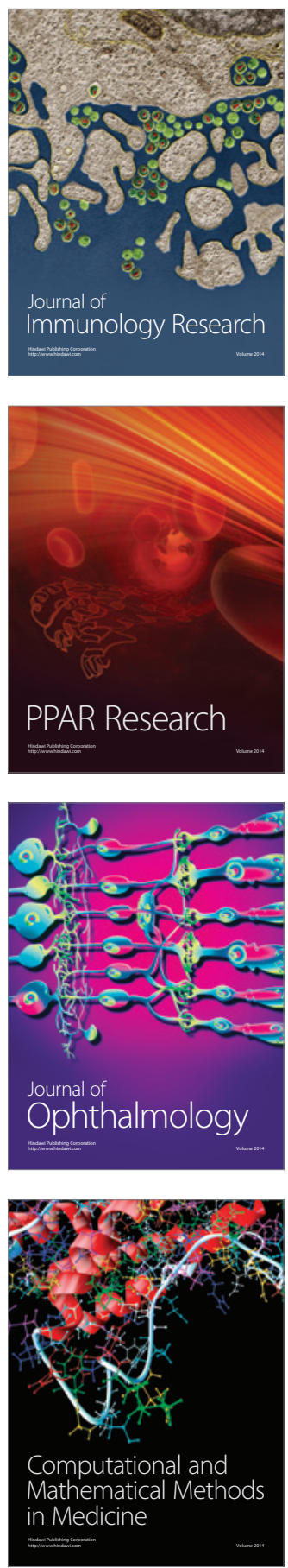

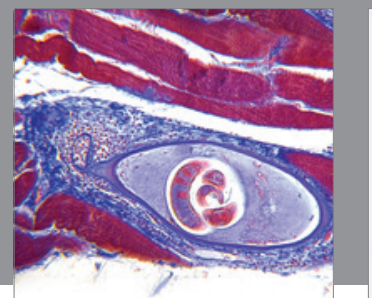

Gastroenterology

Research and Practice
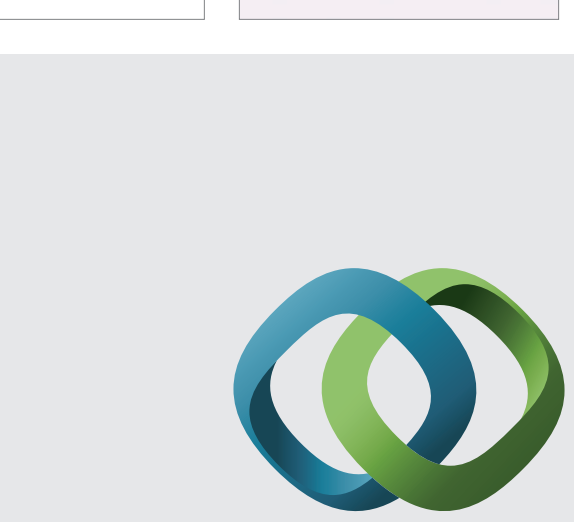

\section{Hindawi}

Submit your manuscripts at

http://www.hindawi.com
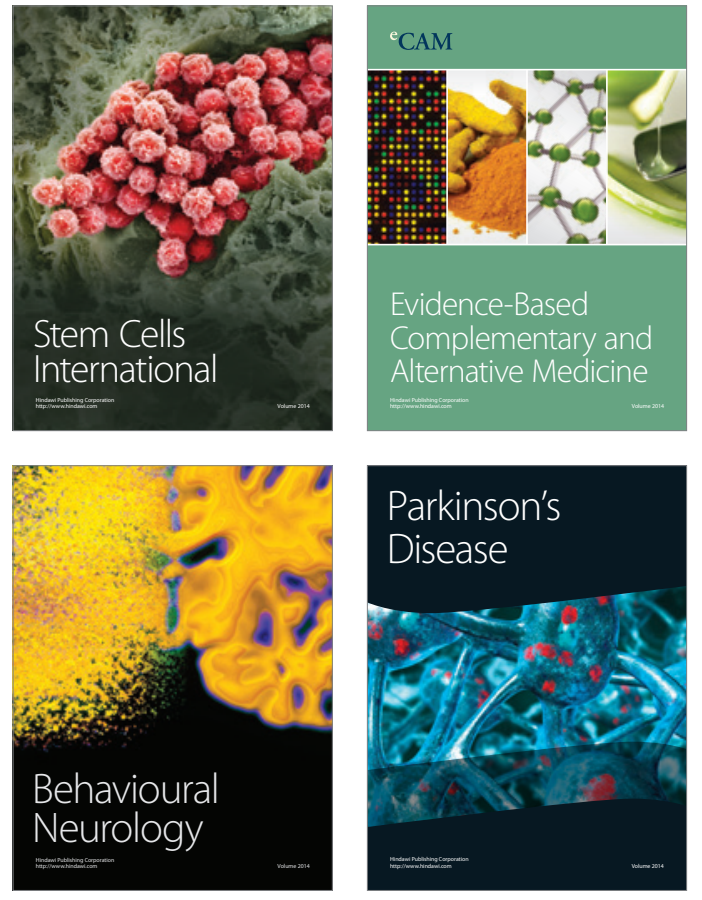
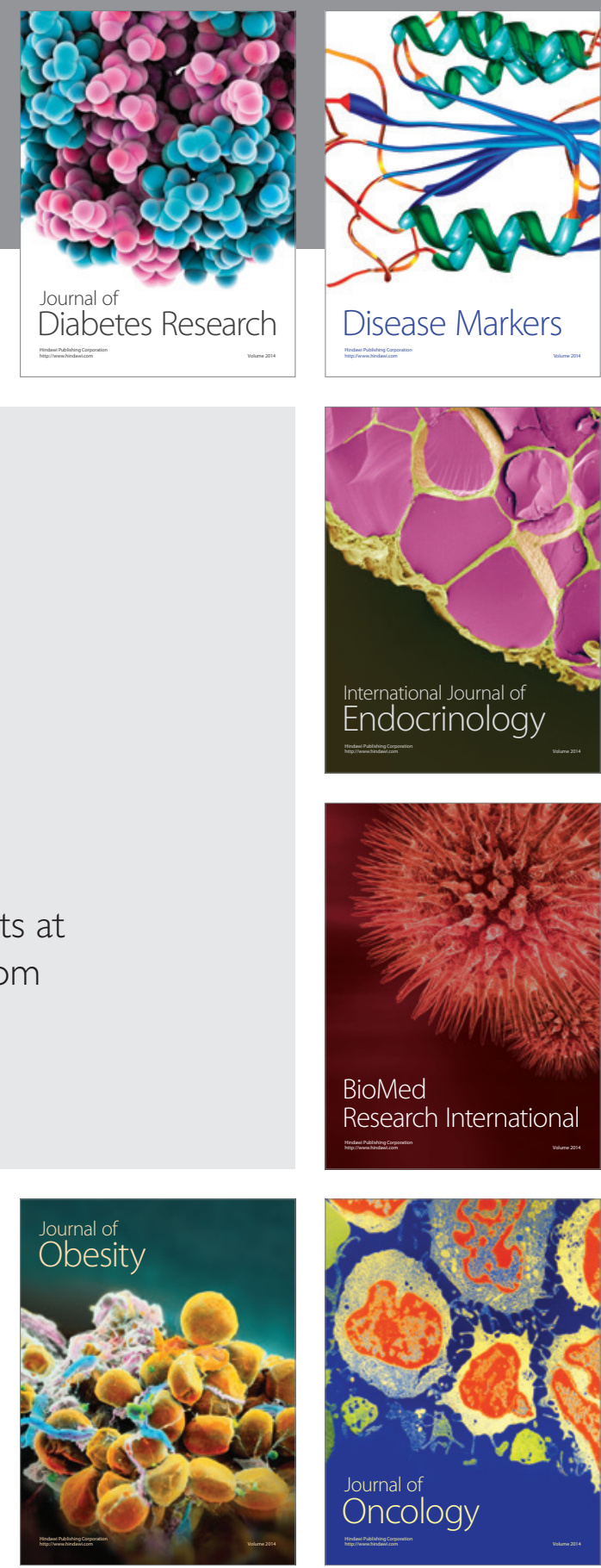

Disease Markers
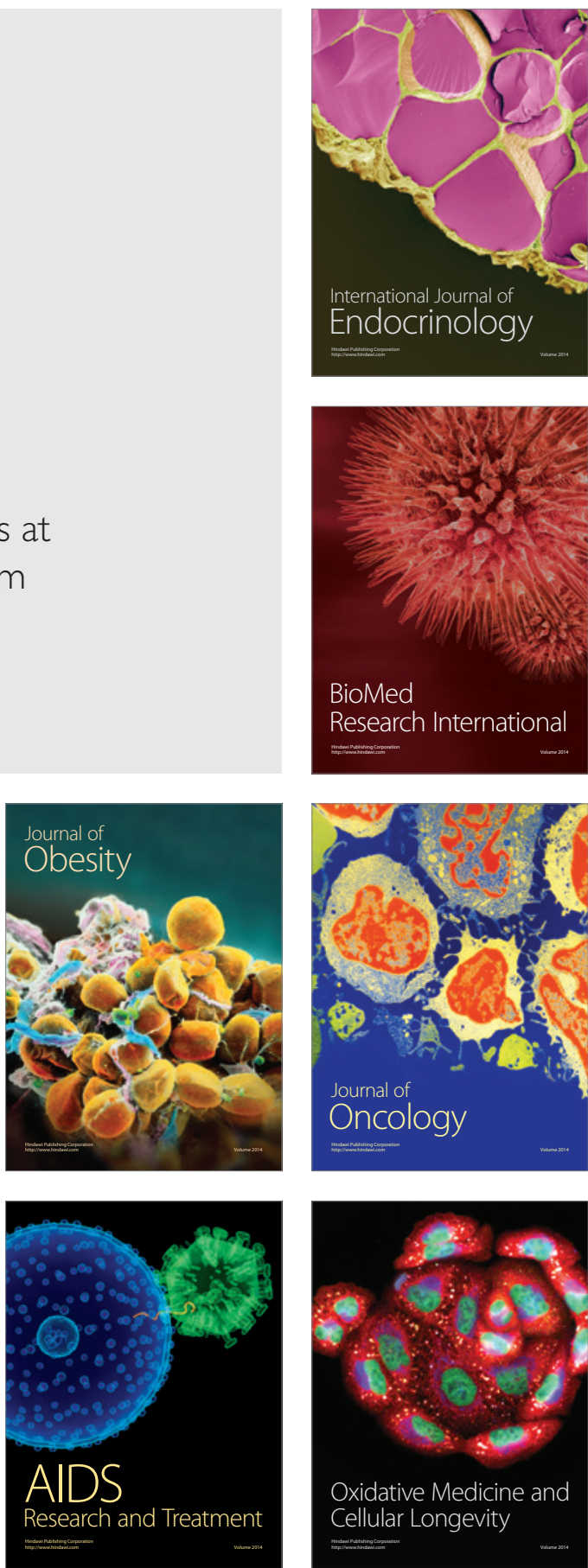